\title{
RETHINKING IMPACT
}
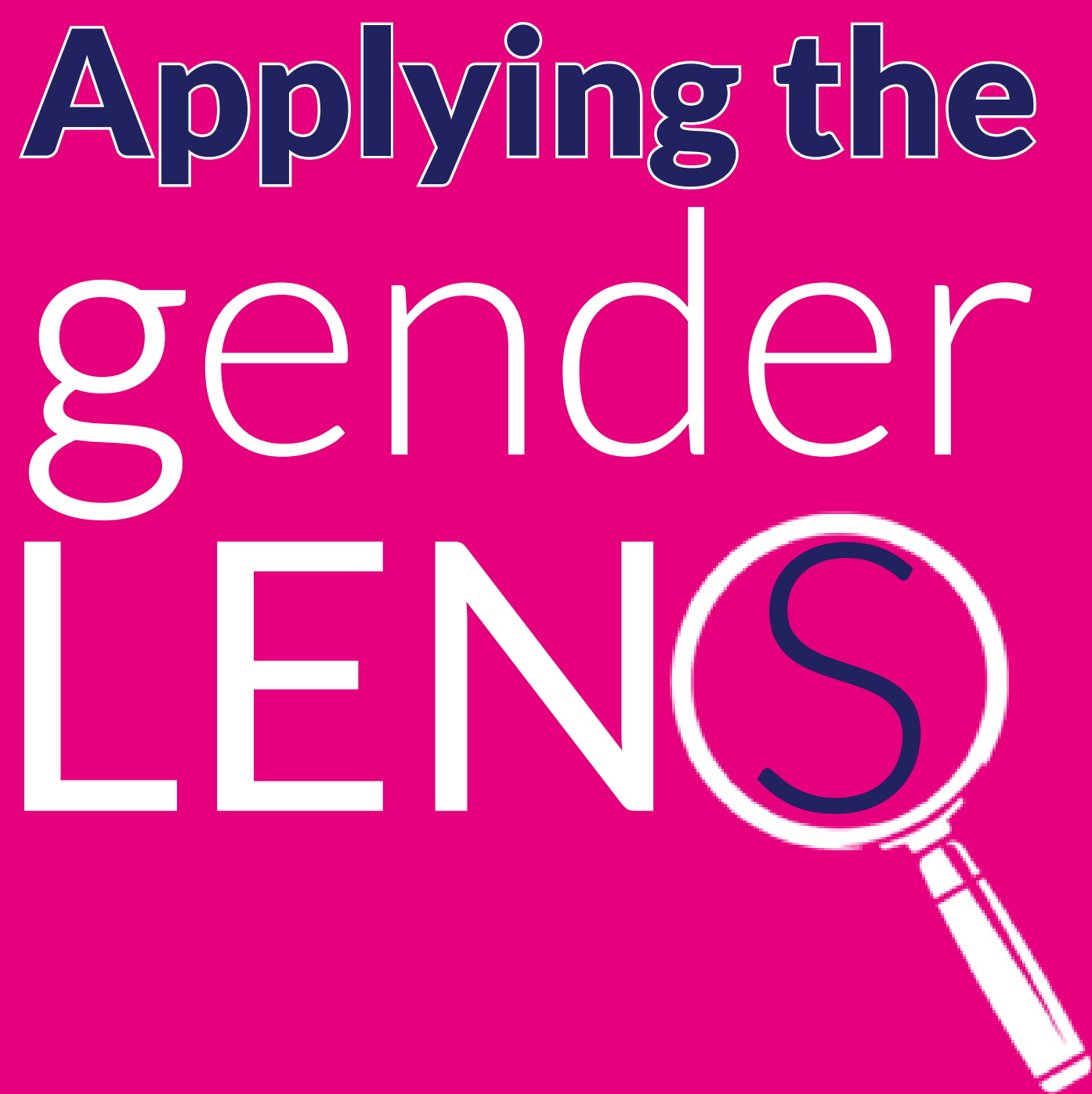

\section{THE IMPACT INITIATIVE}




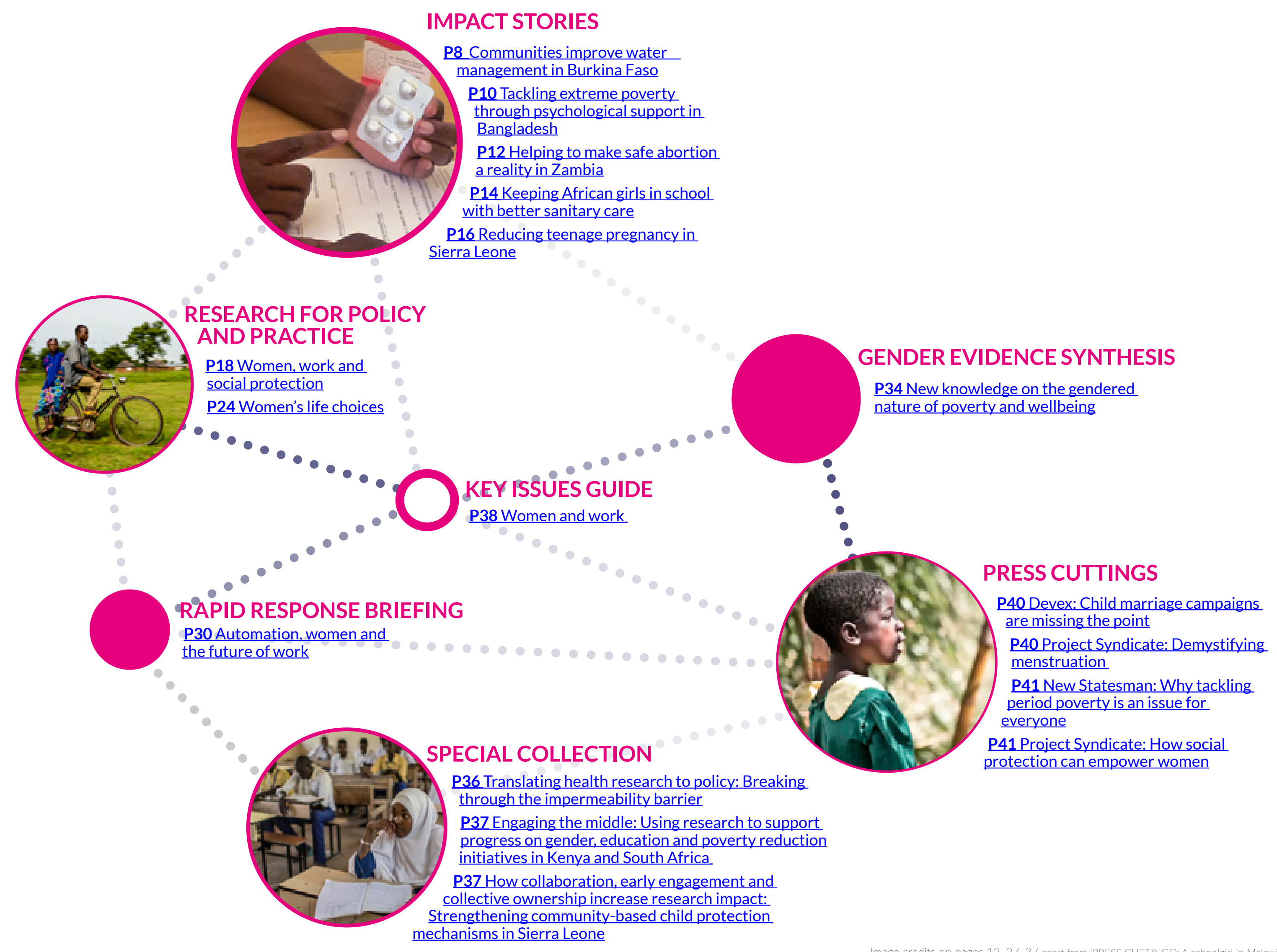

MPACT STORIES

ity in Zambia

Keeping African girls in schoo

PaPen and 


\section{A GUIDE TO THE RESOURCES}

This gender pack profiles the wide array of resources that serve different audiences and purposes. While this pack is solely highlighting how projects have in some way 'applied the gender lens', The Impact Initiative produces resources across many themes:

IMPACT STORIES provide 'easy access' to impact within the projects funded by the ESRC-DFID Strategic Partnerships, along with insights into how the research contributes to wider development issues.

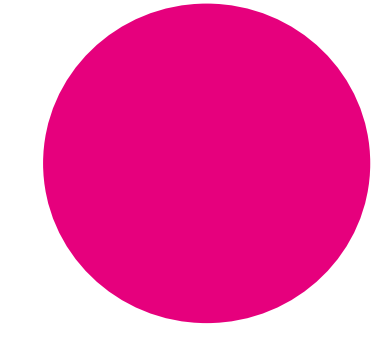

RAPID RESPONSE BRIEFINGS aim to make research widely available and accessible to a range of noncademic audiences, and ensure its relevance is recognised by policy actors and practitioners.
The GENDER EVIDENCE SYNTHESIS RESEARCH AWARD was funded by the ESRC-DFID Strategic Partnership to provide a review of the contribution to understandings of gendered poverty made by awards financed under the ESRC-DFID Joint Fund for

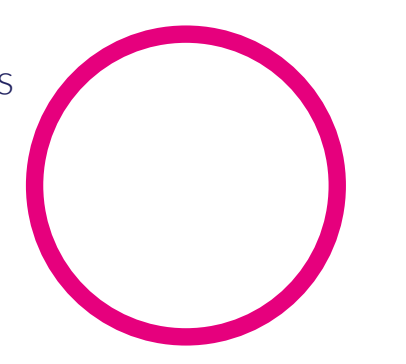

The SPECIAL COLLECTION of articles published by The Impact Initiative and The Institute of

Development Studies, 'The Social Realities of

Knowledge for Development', provides an analysis of

the critical challenges faced by organisations and individuals

involved in evidence-informed development through a diverse set of case studies and think pieces.

The KEY ISSUES GUIDES are online, and presented in partnership with Eldis, offer a concise and accessible introduction to key development issues and aim to introduce research evidence to a broad global audience of development practitioners, decision-

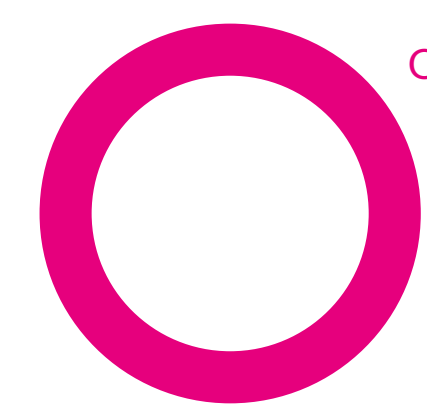

PINION PIECES (AKA PRESS CUTTINGS) are editorials written by researchers, often in partnership with NGOs and/or policymakers and published in media outlets to reach a policy and public audience. These pieces are opportunities to contribute and engage in broader and topical debate that is connected to the research projects.

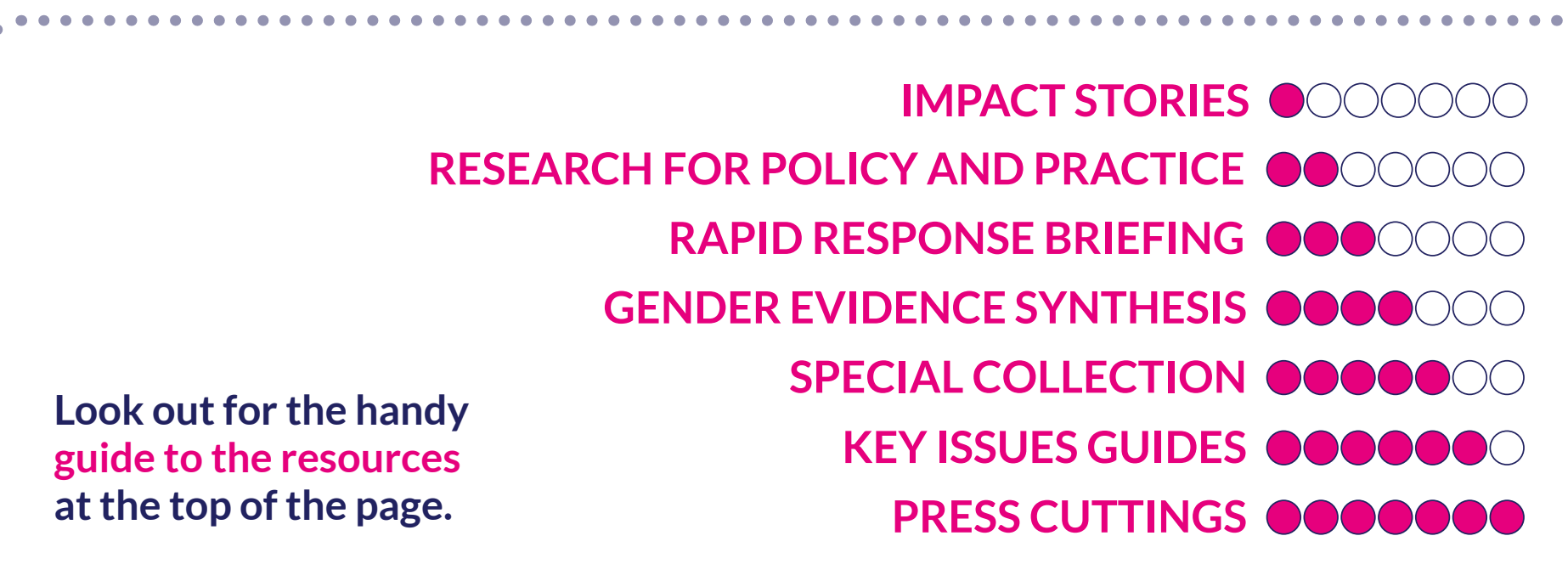




\section{COMMUNITIES IMPROVE WATER MANAGEMENT IN BURKINO FASO}

Globally, water scarcity and poor water quality have a major impact on food security and livelihoods. While there has been significant progress in the past decade, and over 90 per cent of the world's population now has access to clean drinking water, there is still a long way to go to reach the most marginalised and ensure that water is protected from degradation. The set-up of 'Innovation Platforms' in Burkina Faso around two small water reservoirs meant that diverse members of rural communities, agricultural agents, and NGOs could reconcile differences and manage their most precious resource in harmony.

\section{THE CHALLENGE}

Burkina Faso is one of the world's poorest countries,

with a high dependence on agriculture for its economy. Natural disasters and adverse weather conditions mean that sustaining a livelihood in rural areas beyond a single season is difficult and often incredibly contentious.

In Boulgou, a province in the Centre-East region of Burkina Faso, 16 villages rely on two water reservoirs for their livelihoods. This is especially true in the dry season when there is little water. But with many people
using it for different purposes, including herders, fishers using it for different purposes, including herders, fishers
and horticulturalists, conflicts and misunderstandings undermined the governance of the water.

Water Management Committees were set up by the state, including local and state actors such as village chiefs and deputies to oversee the management of the reservoirs. Yet in reality, the elder men farmers representing the local communities could not represe the views and lives of the whole community, including poor women, herders, and fishermen from a different ethnicity.

\section{THE RESEARCH}

The ESRC-DFID-funded project 'Pathways out of poverty for Burkina Faso's reservoir-dependent communities' created Innovation Platforms (IPs) - spaces for face-to-face learning, exchange, and negotiation.

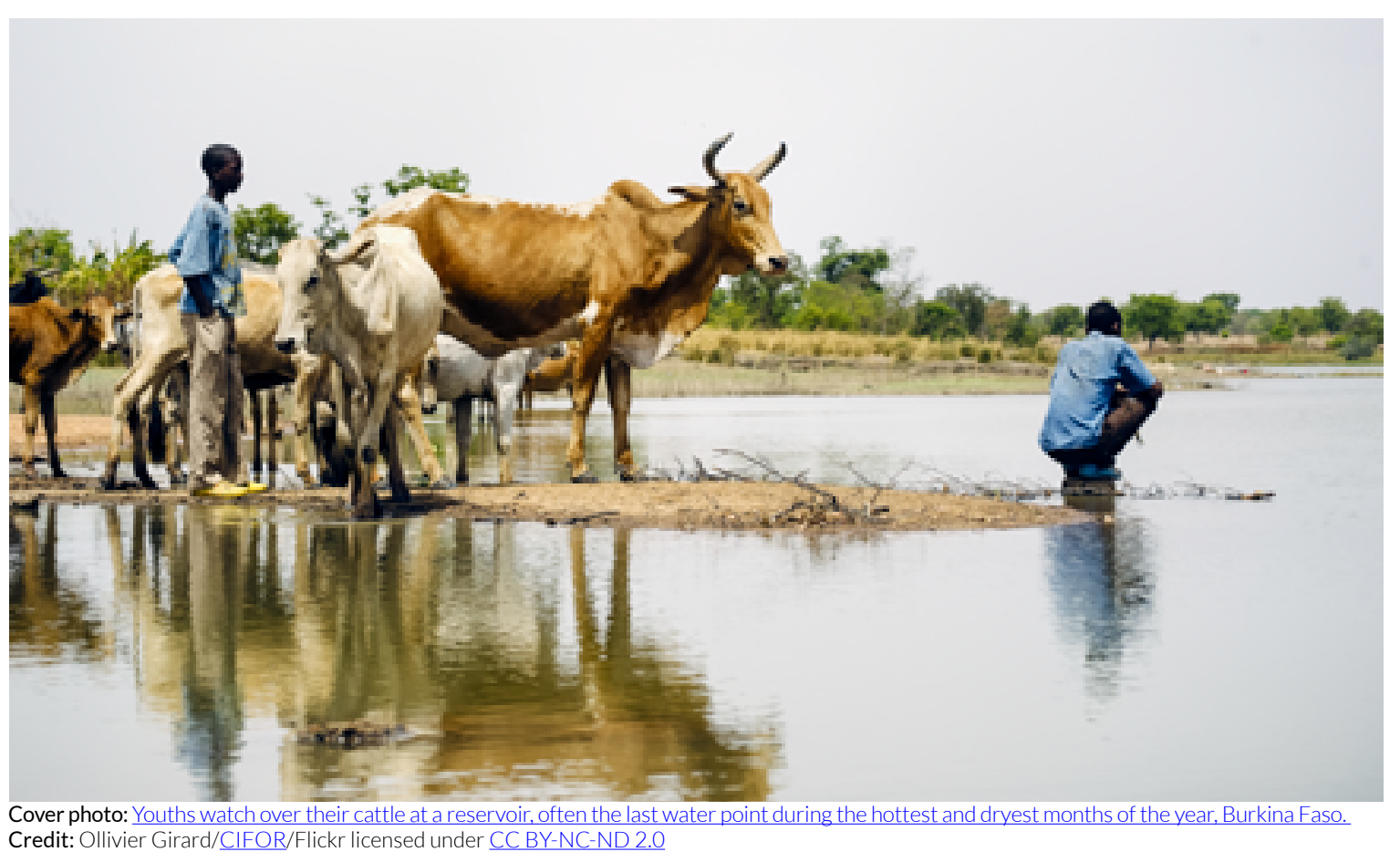

The project supported communities, state and nonstate actors (NGOs) to participate in several meetings and discussions to enhance management of water and make it more equitable.

Communities came together during 2018 to discuss the problems and prioritise solutions around managing small water seservolis. Parlicipants worked within peer groups, i.e. elder men, younger men, women, and state and $\mathrm{NO}$ actors, and then came together in plenary. his process show don which included the application of fertilisers by some overfishing and herders trampling farmers' crops wen bringing their animals to drink.

Together they set out a clear action plan to create an inclusive community governance committee to manage the reservoir, to increase the height of the dykes and rehabilitate the reservoir channels, and to train

\section{THE IMPACT}

Women are now much more involved in the reservoir management process than they had been before. growing vegetables adjacent to the reservoir was very contentious as there was not enough land for everyone and residents were concerned that it caused a drop in the reservoir's water level. Despite the hig stake that vegetable growers had in managing the reservoir women were not included in discussions or in decision-making committees. Through the platforms, the importance of women's participation in reservoir management has been recognised, and they have created a sub-group to advise a new water users committee.

It has also been recognised that young people have an important role to play to bring about change in the future. As a result of the project, young men have taken committees. Furthent and vice president in one of the has been created, and 2018 was the first year that the fishermen have respected 'fishing blackouts' and not used small meshed nets that capture immature fish. Herders are now using livestock corridors to avoid damaging farmers' crops.

The communities have also rallied and raised funds to realise some of the solutions that they have identifed. For example they hired professionals to unblock a main channel to improve flow into the reservoir and invited state water technicians to provide guidance throughout the process.
As a regional agricultural extension agent, Kyelem Richard, explained, 'There is a good collaboration with communities. We understand each other better and they are coming to me to involve me in their activities nd ask for advice'. This is a change from communities viewing state actors as policing a situation to seeing them as a supportive voice.

In striving to achieve Goal 6 of the Sustainable Development Goals - Ensure access to water and sanitation for all - this project clearly recognises the management'

\section{FURTHER READINC}

(2018) Pathways out of Poverty for Burkina Faso's Reservoir-Dependent Communities', presented at the 'Power of Partnership' Conference. cgiar.org/bitstream/handle/10568/99306/Bioversity WaterBF.pdf (accessed 13 February 2019)

Jones, S. and Elias, M. (2018) 'Searching for Pathways towards Equitable and Sustainable Reservoir unw.bioversityinternational oro/news/detail searching-for-pathways-towards-equitable-and sustainable-reservoir-management/ (accessed 13 February 2019)

Policy Support in Water, Environment and

Conservation Management (2018) 'Using WaterWorld Ecosysten Serure to Understand Current and Future http://blog.policysupport.org/2018/02/usingwaterworld-and-coting-nature-to.htm (accessed 13 February 2019)

Pathrays out of poverty for Burkina Faso's reservoirc dependent communities ESPC-DFID's Joint Fund for Poverty Alleviation Research and included Bioversity International, SNY
World, King's College London, and the University of Ouagadougou. 


\section{TACKLING EXTREME POVERTY THROUGH PSYCHOLOGICAL SUPPORT IN BANGLADESH \\ 000000000000000000000000000000000000000000000000000}

In the last 20 years, remarkable progress has been made in tackling extreme poverty.

Yet, while the number of people living on less than US\$1.90 per day in 2015 was

736 million (10 per cent of the global population, down from 11 per cent in 2013),

the rate of poverty reduction has started to decline. Reaching and keeping the most

vulnerable and marginalised people out of poverty is harder than ever. A novel

initiative in Bangladesh, led by the international non-governmental organisation BRAC, to provide material and psychological support to the poorest individuals and households has proved to be a sustainable and lasting way to prevent them from falling back into poverty.

\section{THE CHALLENGE}

THE RESEARCH

\section{Microfinance initiatives (MFIs) are widely used by}

governments and non-governmental organisations

(NGOs) to help the poor to their way out of desperate poverty and to provide a reliable and safe source of income. Yet, in the early 1990s, the global NGO BRAC ecognised that MFIs are not always an appropriate way tosupporthe extrente poor as hey aril to take into account the psychological, cultural, and physical barriers that prevent people from setting up and malit taining therrown small businesses. Women male-dominted socety andedandisolatedina

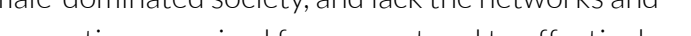
the loan successfully.

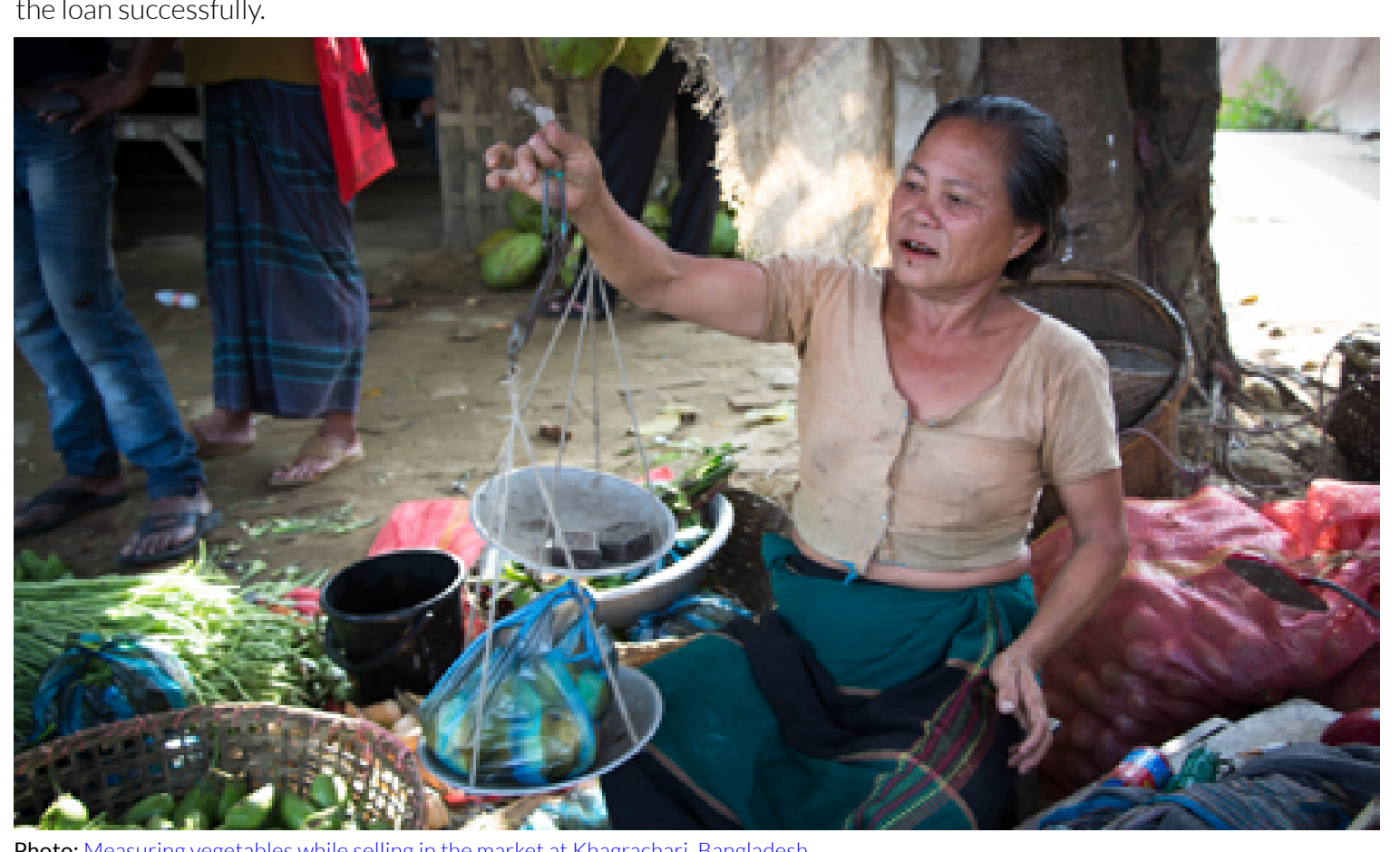

Through BRAC's Challenging the Frontiers of Poverty Reduction: Targeting the Ultra-Poor (CFPR-TUP) ( worked on the pogic that those living inis programme were illiterate they required training to take care of their 'business' assets - ie a cow a flock of chichens, or a small grocery shop. That logic extended to the understanding that in order to beneft from having these assets the families have to be well looked after. Each family was provided with acse worker who needed some kind of 'asset transfer' 'Since most
The ESRC-DFID Joint Fund for Poverty Alleviation Research funded the Graduation as Resilience programme through two stages from 2013 to 2018 to (D) derstand what aspects of BRAC's already successful SFPR-TUP programme could be replicated. In the first wellbeing and used it on a sample of women from the CFPR-TUP to find out how well they could manage specific tasks, such as looking after their assets, and the level and type of support they had received to enable them to do so.

The second phase of the programme tested the new 'psychosocial' model in three programmes in Bangladesh to see if it worked on a broader scale - it included one BRAC programme (CFPR-TUP) and two government-supported programmes carried out by Palli Karma-Sahayak Foundation (PKSF). The research asked 1,800 households across the programmes about what aspects helped people get out of poverty and showed overwhelmingly that the case-by-case support

\section{THE IMPACT}

The assessment of the CFPR-TUP and roll-out of the model showed that the success of the CFPR-TUP was not an isolated example. Ninety-five per cent of participants in phase 2 of the research graduated from poverty in Bangladesh. The UK government's Department for International Development (DFID), Australla's Department of ForeignAffairs and Trade. and others continue to fund this programme. Based on the evidence, DFID encouraged other organisations to take up the approach and funded other major programmes in Bangladesh based on the same model. The model was copied globally with support from the Consultative Group to Assist the Poor (CGAP), the Ford Foundation, and other donors.

A major research study, published in Science Magazine, produced compelling evidence of the success of 'Graduation' pilot projects in Ethiopia, Ghana,

Honduras, India, Pakistan and Peru, and the approach is now being promoted globally by the World Bank and other major international development actors. As the six-cuator of the CGAP and Ford Foundation-funded six-country programmes concluded, a multifaceted ultra-poor [the BRAC income and wellbeing or the cost-effective.
The Graduation as Resilience research has shown overwhelmingly the success of incorporating a more olistic approach to addressing extreme poverty. As the global community strives to achieve the Sustainable Development Goals by 2030, it is those in extreme poverty who remain the hardest to reach and support. By evaluating the successful BRAC programme, and working closely with the Bangladeshi government, is evident that there are components that can be afield.

\section{FURTHER READING}

Baneriee, A. et al. (2015) 'A Multifaceted Program Causes Lasting Progress for the Very Poor: Evidence from Six Countries'. Science 348.6236. doi:10.1126 9 (accessed 26 October 2018)

Bandiera, O. et al. (2017) 'Labor Markets and Poverty in Village Economies'. The Quarterly Journal of Economics

\section{October 2018)}

Raza. W.A.: Van de Poel, E. and Van Ourti, T. (2018) Impact and Spill-over Effects of an Asset Transfer a Randomized Control Trial in Bangladesh'. Journal doi-101016/ijhealeco 201809.011 laccessed 26 October 2018)

Mahbub. U. (2018) Can Empathy End Poverty? BRAC blog, 25 September, http://blog.brac.net/can-empathyend-poverty/ (accessed 26 October 2018

Graduation as resilience Graduation as resilience stage two

列 Alleviation Research, led by Mushtaque Chowdhury, BRAC, Banglades 


\section{HELPING TO MAKE SAFE ABORTION A REALITY IN ZAMBIA}

Zambia has one of the most liberal abortion laws in sub-Saharan Africa. However in spite of this, unsafe abortion continues to contribute to high rates of maternal mortality. Stigma, poverty, conscientious objectors, and lack of knowledge all contribute to why many adolescent girls and women do not and cannot access safe abortions in Zambia. Through ground-breaking research led by the London School of Economics and Political Science (LSE), political, media, and charitable organisations are now making changes to raise awareness and shape their frameworks to ensure women can take up their right to access safe abortion services.

\section{THE CHALLENGE}

Under the Termination of Pregnancy Act of 1972

Zambian law asserts that women have the right to safe and legal abortion services. But very few people know about the law, or the services available, and there is still an enormous amount of stigma associated with abortion.

Worldwide, approximately 25 million unsafe abortions are carried out each year and death from unsafe abortion disproportionately affects women in Africa (WHO 2018) In Zambia the government estimates that 30 per cent of maternal deaths are attributable to unsafe abortion.

\section{THE RESEARCH}

chers wanted to understand the roles that the health system, poverty, and stigma can play in seeking abortion-related care in Zambia; estimate and compare the implications of safe abortion and post-abortion care for women and their households; and ultimately better understand how and why safe abortion services are not used more fully.

Based at a Zambian Government Health Facility in Lusaka, the researchers interviewed over 100 girls and women coming either for an abortion or for postabortion care after an unsafe abortion. The research wed closely with midwives to gain informed and considered consent from all the participants.

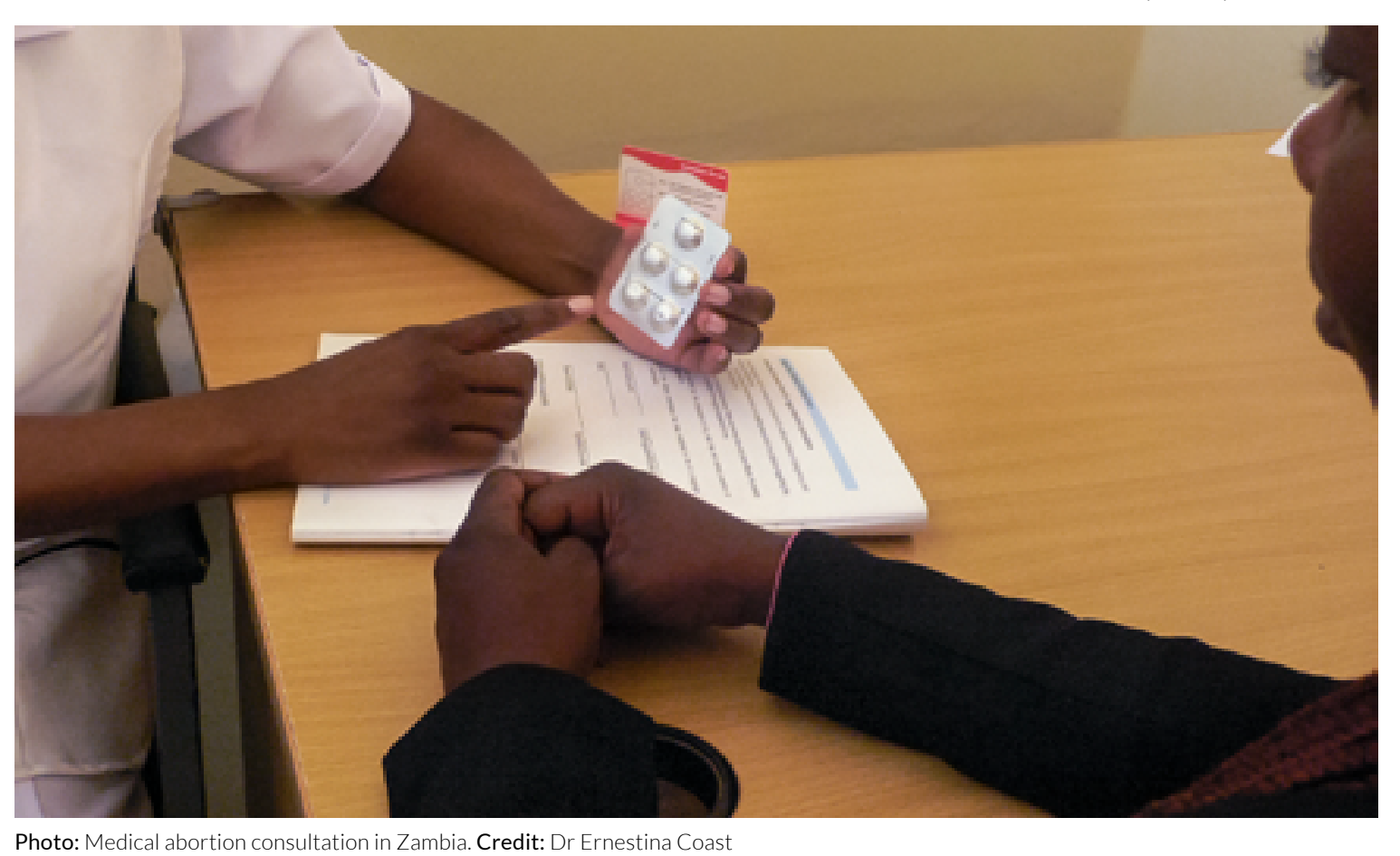

In addition to the dangerous and often life-threatening impact of unsafe abortion, the research identified a significant public health cost The first national estimates showed that treating the consequences of unsafe abortion costs the Zambian health system up to US\$0.4 million more than if the pregnancies had been terminated safely and legally.

The study found that younger and poorer women are more likely to have an unsafe abortion, even though the costs of per centhigher than the costs associated with a safe abortion. It also revealed that women often have to make 'unefficial payments' to doctors for services that should be free.

'Luck' or 'chance' plays a primary role in determining whether a woman can have a safe and legal abortion. Quite often, where a woman feels she can disclose to someone that she is pregnant or if she knows someone in the health sector she may get the services she needs. Otherwise, women may not know these services exist, and fr they need to hide their pregnancy or order to terminate an

Raising awareness of these services - targeting not just the general population, but also health professionals - is vital if the Zambian Government is to reap the rewards of their investment in the provision of safe and legal abortion services.

\section{THE IMPACT}

The research team have been - and continue to be - proactive in engaging key people, organisations, and institutes to support progress to successfully implement and deliver safe and legal abortion services. Through working with government, media, and nongovernmental organisation (NGO) actors, his research has gone beyond Zambia solely as a country study, and is shining a spotlight on the complex and challenging process of how to provide abortion care.

Media engagement has included the researchers being involved in training Zambian radio producers who work on programmes for young adults. In-country partners also gave interviews on BBC World News, and programmes on the Zambian National Broadcasting Corporation (ZNBC), commercial radio, and a radio station for young adults.
The Zambian lead for the project presented the findings to the Resident Doctors Association of Zambia (RDAZ) in 2015, during which he found that newly graduated. doctors were unaware of the laws around abortion in Zambia. The guest of honour was the Deputy Minister of Health, who subsequently invited the partner to present at the Senior Management meeting of the Ministry of Health. The research has also been incorporated in the latest Standards and Guidelines for tion Care in Zambia.

\section{FURTHER READING}

mics) (2015) Zambia

Urged to Tackle the Stigma of Abortion and Unwanted Pregnancies', Firoz Lalii Centre for Africa blog, 11 June, http://blogs.Ise.ac.uk/africaatlse/2015/06/11/zambiaurged-to-tackle-the-stigma-of-abortion-and-unwantedpregnancies/ (accessed 28 June 2018)

Parmar, D.; Leone, T.; Coast, E.; Fairley Murray, S.; Hukin. E and Vwalika, B (2017) 'Cost of Abortions in Zambia: A Comparison of Safe Abortion and Post Abortion Care', LSE Research Online, http://eprints. Is.ac.uk/63643/1/ Ise.ac.uk storage LIBRARY Secondary libfile_shared_repository Content Coast.\%20E_Cost\%20of\%20abortions Coast cost\%20of\%20abortions_2016.pdf (accessed 28 June 2018)

WHO (2018) WHO Preventing Unsafe Abortion, World Health Organization Fact Sheet, www.who.int/newsroom/fact-sheets/detail/preventing-unsafe-abortion (accessed 28 June 2018)

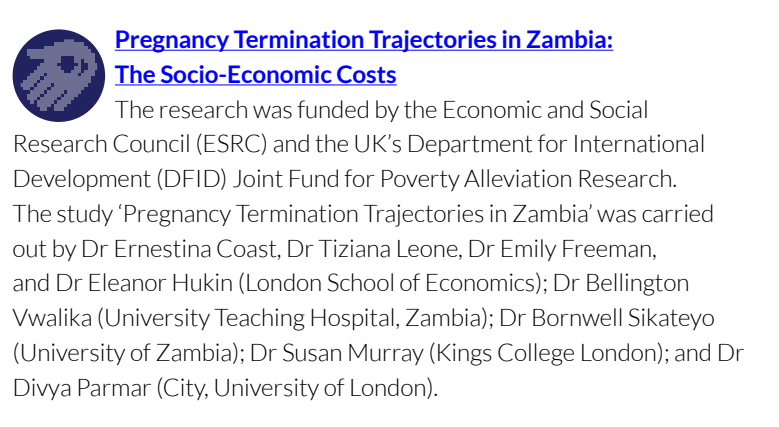




\section{KEEPING AFRICAN GIRLS IN SCHOOL WITH BETTER SANITARY CARE}

Cor young girs in developing countries, notknowinghow to mana. hinder access to education. Research from the School of Oriental and African Studies (SOAS), University of London demonstrates that in rural Uganda, providing free sanitary products and lessons about puberty to girls may increase their attendance at school.

\section{THE CHALLENGE}

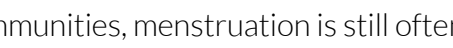
seen as an embarrassing, shameful, and dirty proces. Such taboos around the topic mean many adolescent girls are often unprepared for their periods and how thiddle-inceme coss than hall of girls in lower- and sanitary towels or tampons soap and water or fail ties to change, clean, or dispose of hygiene products.

In Uganda, only 22 per cent of girls are enrolled in secondary schools compared with 91 per cent in primary schools, with those living in rural areas bein believe that the cos to go to school. Researchers

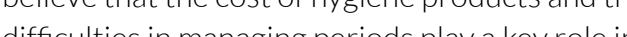
keeping girls out of school.

\section{THE RESEARCH}

Over 24 months, a trial was conducted in partnership with Plan International Uganda across eight schools, involving 1,008 girls, in Uganda's Kamuli District, an are well as gender disparity in health and education

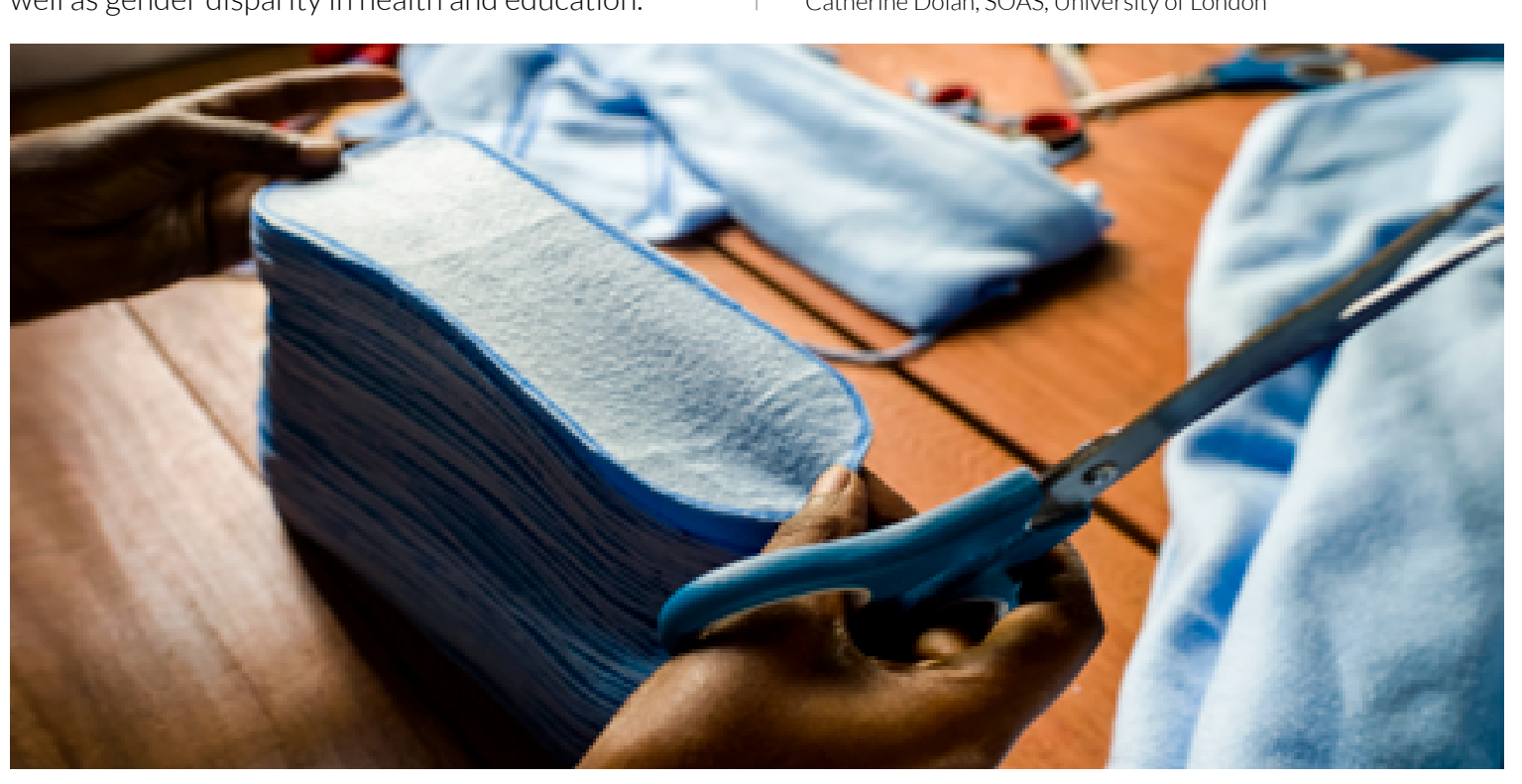
sanitary pads, (b) adolescent reproductive health delivered over two years, did appear to improve

\section{THE IMPACT} awareness that sanitary pad provision and puberty education are both vital in improving attendance. Even the research recommends that inclusion of adequate and gender-sensitive puberty education in the school curriculum can improve attendance.

Organisations such as UNICEF and the NGO CARE have used the evidence to identify solutions to barriers to girls'

improved when girls were given (a) reusable education, (c) neither, or (d) a combination of both. Girls were provided with AFRIpads, a washable, reusable cloth pad produced in Uganda, and locally trained community health nurses held sessions that covered changes which occur during puberty, menstruation, and early pregnancy, and on the prevention of HIV. Researchers found that better sanitary care and reproductive health education for poor schoolgirls, attendance. On average, girls increased their attendance by r

Many girls don't know about periods before they encounter their first one. They are totally or trainin on how to mana them Simp terventions like these can have major conomicimplications for women in low- and middle-income countries. barriers that keep gir sout of school. All over civil
These findings will make an important contribution to CARE's efforts to fight poverty by removing the for large-scale rollouts because of the hard evidence provided by the study in Uganda. Joan Garvey Lundgren, Executive Director, Strategl
Partnerships, CARE USA

The project collaborated with Save the Children, the United Nations Educational, Scientific and Cultural Organization (UNESCO), WaterAid, and AFRIpads to bby for menstrual hygiene management to be included an indicator in post-2015 sustainability goals.

Further collaborations building on the evidence have the distribution with Save the Children on how to link programmes, and with UNESCO on effective programming puberty education and menstrual hygiene manegement. Ghana's Deputy Minister of Education referenced the research when defending the decision to allocate part of the country's 2014 World Bank loan to providing sanitary pads for female students in need. Samuel kudzeto Ablakwa stated that when adolescent girls 作

The research team continues to use the results as part of a push to promote female hygiene onto the global development agenda. The findings featured in preparatory documents for he World Health Organization (WHO) UNICEF Joint Monitoring Programme indicators for UNESCO Puberty Educations M, and have beencited in the

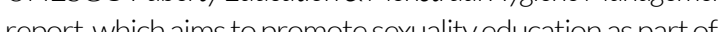
skills-based health education for young people

The impact of the research has the potential for addressing psychosocial wellibeing, dignity, comfort, a ability to manage menstruation without shame, which are all essential for girls responding to the challenges
D

as this are too few and far between They are critical to give context to the impact of and sanitation during puberty, which in girls' life chances. Brooke Yamakoshi, Water, Sanitation and Hygiene (WASH)
Specialist Sanitation and Hygiene), United Nations Children's

\section{FURTHER READING} and Scott, L. (2014) 'A Blind Spot in Girls' Education: Menarche and its Webs of Exclusion in Ghana', Journa Of International Development 26.5: 643-57

Hennegan, J.; Dolan, C.; Steinfield, L. and Montgomery P. (2017) A Qualitative Understanding of the Effects Implications for Future Research and Practice', Reproductive Health 14.78

Hennegan, J.; Dolan, C.; Wu, M.; Scott, L. and Montgomery, P. (2016) Measuring the Prevalence and Impact of Poor Menstrual Hygiene Management. A Quantitative Survey of Schoolgirls in Rural Uganda', BMJ Open 6.12.1-14

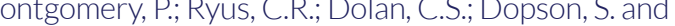
Education in Ghana: A Pilot Study' PL OS ONE 7.10: e $48274^{\prime}$ Montgomery, P.; Hennegan, J.; Dolan, C.; Wu, M.;

Steinfield, L. and Scott, L. (2016) 'Menstruation and the Cycle of Poverty: A Cluster Quasi-Randomised Control Trial of Sanitary Pad and Puberty Education Provision in Uganda', PLOS ONE 11.12: e0166122

Hennegan, J.; Dolan, C;; Wu, M.; Scott, L. and

Montgomery, P. (2016) 'Schoolgirls' Experience and Appraisal of Menstrual Absorbents in Rural Uganda: A Reproductive Health 13.1: 143

Hennegan, J. and Montgomery, P. (2016) 'Do Menstrual Hygiene Management Interventions Improve Sact Cilsin Systematic Review' PLOS ONE 11,2:00146985

Menstruation and the Cycle of Poverty: Does the provision ve the attendance and educational outcomes of girls in school?

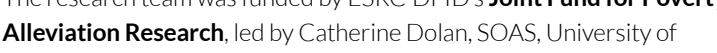
London; Paul Montgomery, University of Birmingham: and Linda Scott. Chatham House. The research was carried out in partnership with Plan Hopkins University;: Marvalice Wu University of Illinois; and Laurel 


\section{REDUCING TEENAGE PREGNANCY IN SIERRA LEONE}

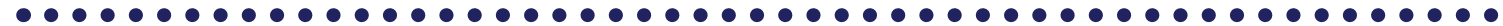

Research directly involving teenagers and their families in Sierra Leone to reduce teenage pregnancy has helped pave the way for a new community-friendly Child and Family Welfare Policy. The research by the Columbia Group for Children in Adversity and UNICEF Sierra Leone mobilised local people through child- and youth-led education initiatives and through closer connections with district health workers. Thanks to the project, condom use increased, teenage girls reported feeling more confident to say 'no' and boys showed more willingness to act responsibly. The findings directly influenced the Sierra Leone government's development of a new policy on child protection.

\section{THE CHALLENGE}

Sub-Saharan Africa has the world's highest teenage pregnancy rates, with one in five girls aged 15 to 19 giving birth. ${ }^{1}$ Many girls who become pregnant are forced to leave school. Complications during pregnancy are common and many girls undergo unsafe abortions. Babies born to adolescent mothers face a substantially higher risk of dying. $\operatorname{In} 2013$, with Sierr Leone recording a 68 per cent pregnancy rate among adolescent girls (with a mean age of 15), ${ }^{3}$ the president

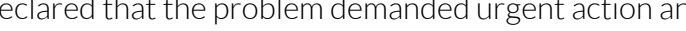
unched a national strategy to address it

Aglobal review of community-based child protection mechanisms, such as Child Welfare Committees, found that these often failed to protect vulnerable early marriage. Problems included a lack of local

ownership deterring families from getting involved, committees collapsing once funding had ceased and poor collaboration between community efforts and district-level health workers. This highlighted a need for a more community-led approach to child protection in places like Sierra Leone, to stem the high rates of teenage pregnancy and prevent the harm it causes to girls' health, their futures and to economic and social

\section{THE RESEARCH}

In 2012 the action research team began working in two districts in Sierra Leone: Moyamba District within the Mende-speaking southern area and Bombali District within the predominantly Temne-speaking northern area. After extended dialogue, community members chose to address teenage pregnancy through family

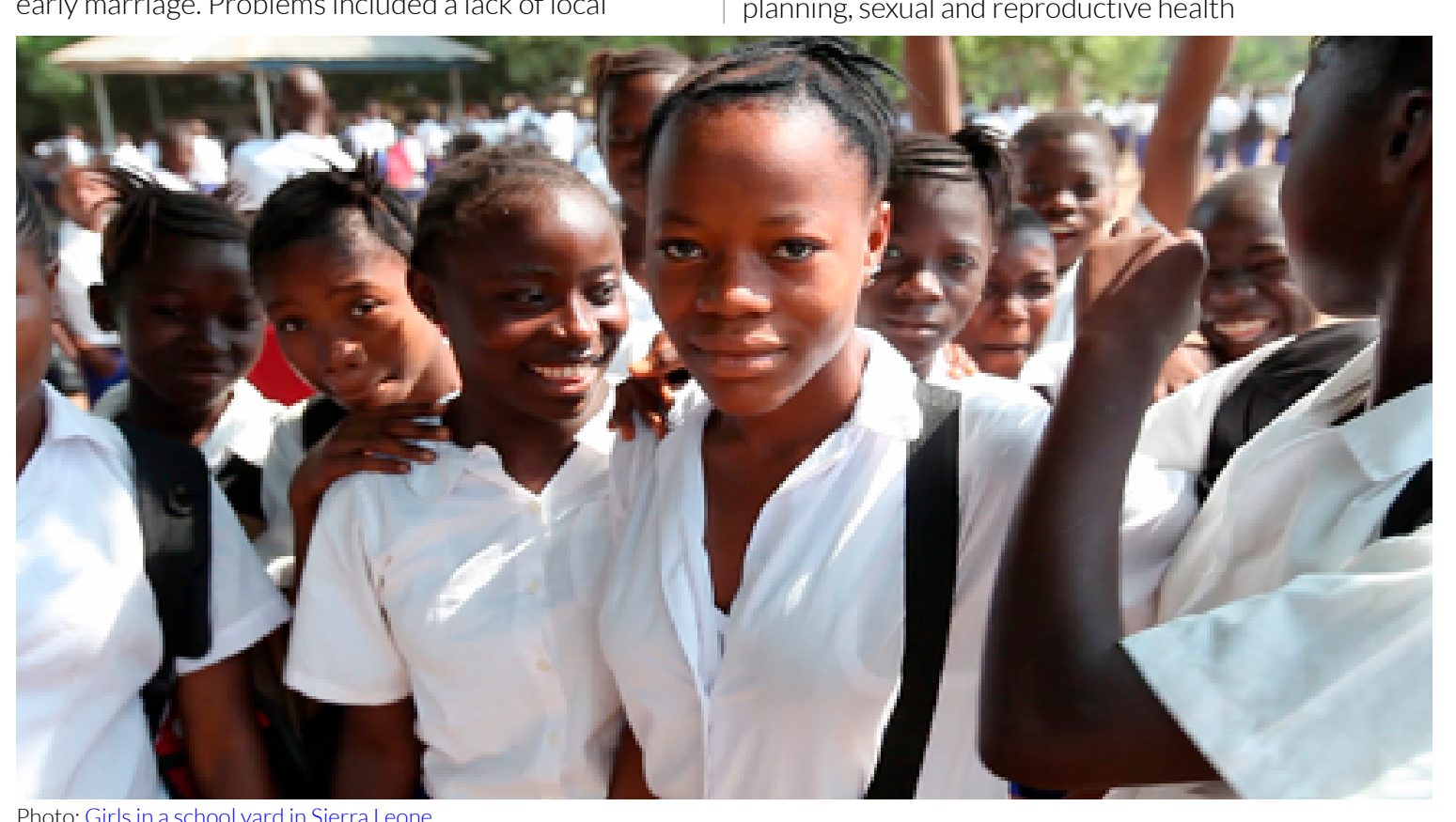

Credit.GPE/Stenhan Bachenheimer licensed under CC BY-NC.ND 2

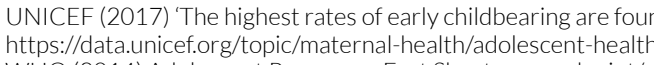

education and life skills. Communities encouraged families to collabor health services and schools. The team coordinated training by NGOs and the provision of contraceptives and education around puberty, sexuality pregnancy and pregnancy prevention by the District Ministry of Health Communities organised role plays among teenage girls and boys while parents and children had candid discussions about puberty sex and preventing pregnancy From the outset, the research team work closely with UNICEF which played a lead role in child protection UNICEF engaged with Sierra Leone's national Child Protection Committee and the Ministry of Social Welfare, Gender and Children's Affairs, whic

\section{THE IMPACT}

A mid-point project evaluation in July 2014 showed that teenagers reported ${ }^{5}$ a greater intent to use condoms while teenage girls reported feeling empowered to refuse unwanted sex more frequently Both girls and boys said that they had learned how to discuss and negotiate with their partners about sex, and how to plan their sexual activities in light of wider life goals. Boys openly acknowledged their responsibility to prevent teenage pregnancy -

r

The insights gave us the evidence we needed to work with the government on
child protection policy.

David Lamin, UNICEF

Health workers, teenagers and their families indicated seeing a significant decrease in teenage pregnancies. Prior to the research, in an average school year there were bive or six teenage pregnancies per village in both districts. In the 2013/14 school year, half the communities reported no new teenage pregnancies, and the other half reportedonlyonenew teenage discuss the problem of early marriage.

Although the Ebola crisis disrupted the project in August 2014, the action research did significantly influence national policy on supporting vulnerable children in Sierra Leone - in particular the findings that local people relied on community-owned processes and existing family and community mechanisms. This directly influenced Sierra Leone's government and UNICEF to collaborate on a new policy placing family-and child-led action at the centre of child protection. The new Child and Family Welfare Policy enacted in 2015 embodied insights from the research.
David Lamin 6 of UNICEF Sierra Leone explained the value of the research: 'The insights into teenage pregnancy and the need for communities themselves drive efforts to protect children provided us with the evidence we needed to work with the government on a radical shift in child protection policy.' He said the fndings were being used to develop ways to implement the policy, adding: 'there are now plans to share this evidence and approach with the governments of Ivory

FURTHER READINC

St. L., Tan, T.. Muldoon, K.A.; King, D.: Lamin, D.: Lilley, S. and Wessells, M.G. (2015)'Family structure adolescents in rural Sierra Leone'. Global Public Health 11.3 www.tandfonline.com/doi/full/10.1080/1744169 2.2015 .1031155

Stark, L.: Macfarlane, M.: King, D.: Lamin, D.: Lillley. S. M. (2014) A community-driven approach to reducing teenage pregnancy in Sierra Leone. Midline Evaluation London' Save the Children

Wessells, M.G. (2015) 'Bottom-up approaches to strengthening child protection systems: Placing Abuse and Neglect: The

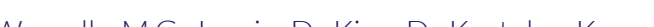
Wessells, M.G.' Lamin. D.: King. D.: Kostellny. K.: and Lilley, S. (2015) The linits of top-down approaches to managing diversity. Iessons from the case of child Conflict: Journal of Peace Psychology 21.4: 574-88

Inter-Agency Research On Strengthening Community-

\section{Was funded by the ESRC-DFID Joint Fund for} Peas Protection

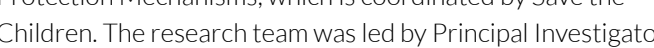
Michael Wessells Columbia University in collaboration with UNICEF, United States

Stark, L. et al. (2014) A community-driven approach to reducing teenage pregnancy in Sierra Leone: Midline Eveluation, London: Save the Children
Wessells, M.G. (2015) 'Bottom-up approaches to strengthening child protection Systems: Placing children, families, and communities at the Wessells, M.G.G. (2015) 'Bottom-up approaches to strengthening
center, CChild Abuse and N Neglect: The International Journal $43: 8$ : 8 -2

\section{Find out more:}

https://www.

theimpactinitiative.net/ resources 


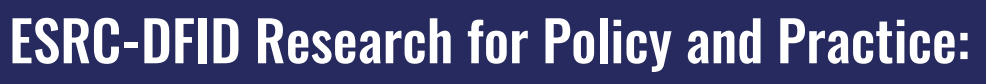 \\ Women, work and social protection \\ March 2019}

\section{Foreword}

\begin{abstract}
To accomplish the 2030 Agenda for Sustainable Development it is absolutely mission-critical to unlock and properly account for women's untapped economic potential and their wider
contributions to society. This must go hand in hand contributions to society. This must go hand in hand
with promoting dignity and self-reliance. Doing so is of direct and urgent relevance to the ambitions that underpin the Sustainable Development Goals related to: ending poverty; achieving gender equality; achieving full employment and decent work for all; and reducing inequality.

When Ela Bhatt founded the Self-Employed Women's Association of India (SEWA) in 1972, she spoke passionately about the need to reframe poverty
alleviation. She said, 'What we really are looking for alleviation. She said, 'What we really are looking for
is self-reliance and that is how we should measure is self-reliance and that is how we should measure
success.'

By adopting a holistic approach to social protection we move beyond an outdated framing of poverty alleviation as being primarily about access to the traditional labour market and cash transfers. To meaningfully tackle persistent poverty - particularly how it manifests for women - social protection must
encompass a much broader range of considerations. The selection of ESRC-DFID-funded research that follows presents pertinent examples of how this applies in practice.

A study in Bangladesh shows that home-based selfemployment, which is overwhelmingly preferred by women, offers considerable advantages despite being excluded from official data and largely overlooked by policymakers. In Rwanda, we see how a national public works programme provides opportunities for significant numbers of women (and by extension their households) to benefit from diversifying their income thus reducing vulnerability to shocks and exposure to risk. A study in Malawi and Lesotho demonstrates that
\end{abstract} while cash transfers have a role to play in shoring

the living standards of some of the poorest women, they have limited utility with regard to enabling them contribute in a full and satisfying way to their communities. A study from South Africa demonstrates that basic employment alone is not enough to tackle the lack of dignity that characterises the experience of so many women living in or on the margins of poverty. While undeniable strides have been made towards gender equality in recent decades, more often than not this has happened in spite of rather than because of the prevailing approaches to economic policy and social protection. Typically, traditional modes of thinking result in missed opportunities and suboptimal utcomes for women because they fail to recognise and address the complexity and nuances of women's experiences, needs and contributions to the economy. Until these things are routinely addressed, Ela Bhatt's vision of self-reliance for all women and the ambitions of the 2030 Agenda for Sustainable Development will remain elusive.

Mandu Reid

National Spokesperson for the UK Women's

Equality Party

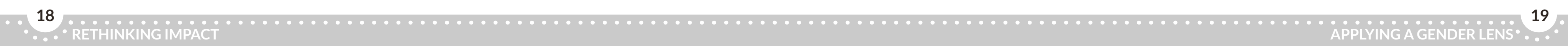

\section{Key messages}

- Policymakers should use frameworks that recognise and capture the economic impact of all relevant activities undertaken by both genders, including unpaid work and caring obligations, the lion's share of which falls to women.

- Social protection strategies for women surviving on very low incomes must go beyond cash transfers and include measures that uphold dignity and promote self-reliance, such as incomegenerating schemes.

- Where policy is focussed on providing women with access to the traditional labour market, the quality of employment opportunities must be considered alongside measures that support women juggling household and caring responsibilities for children and other family members.

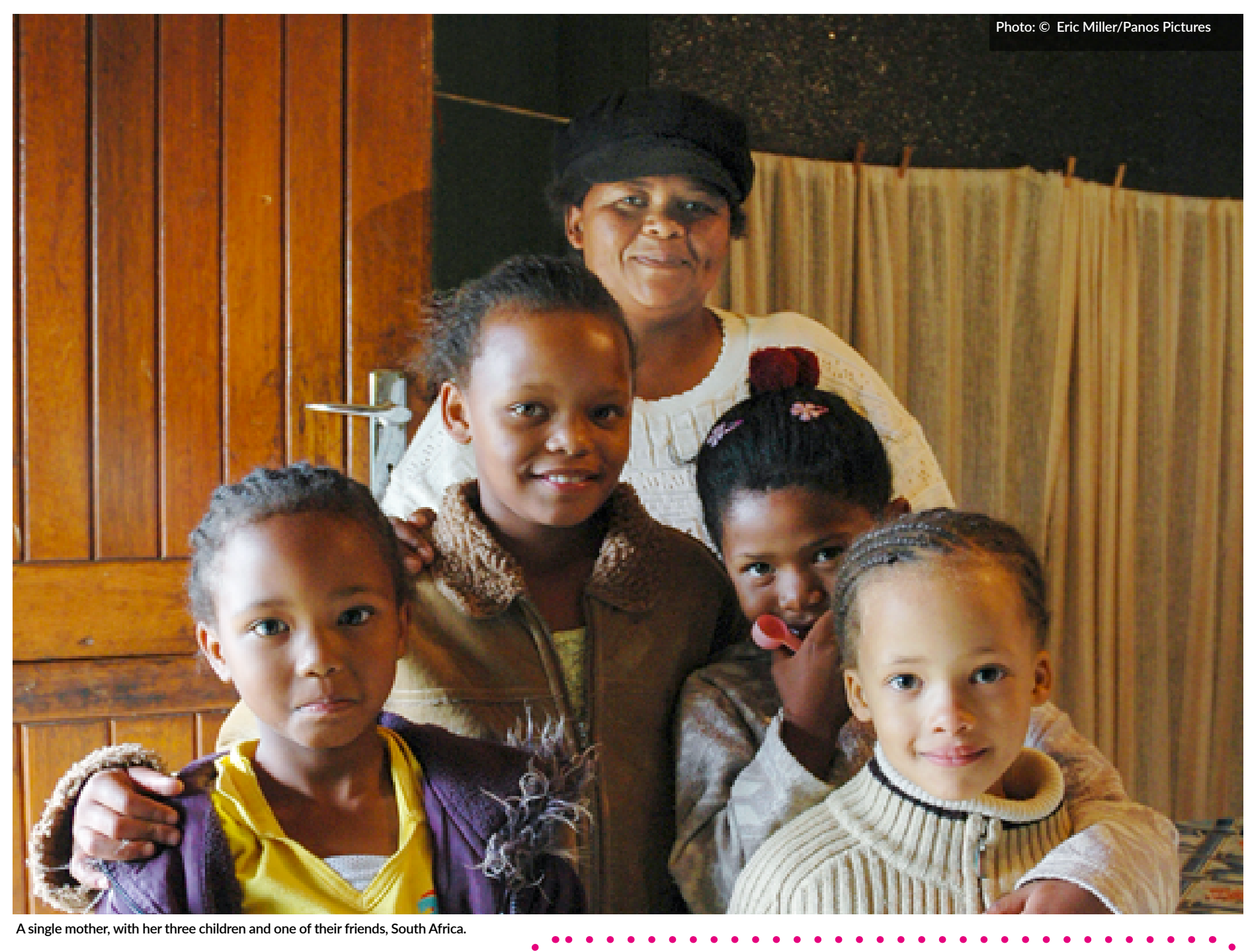

Find out more:

- https://www.theimpactinitiative.net/resources/ : esrc-dfid-research-policy-and-practice-women- : work-and-social-protection 
Public works in Rwanda led to increased female non-farm labour supply

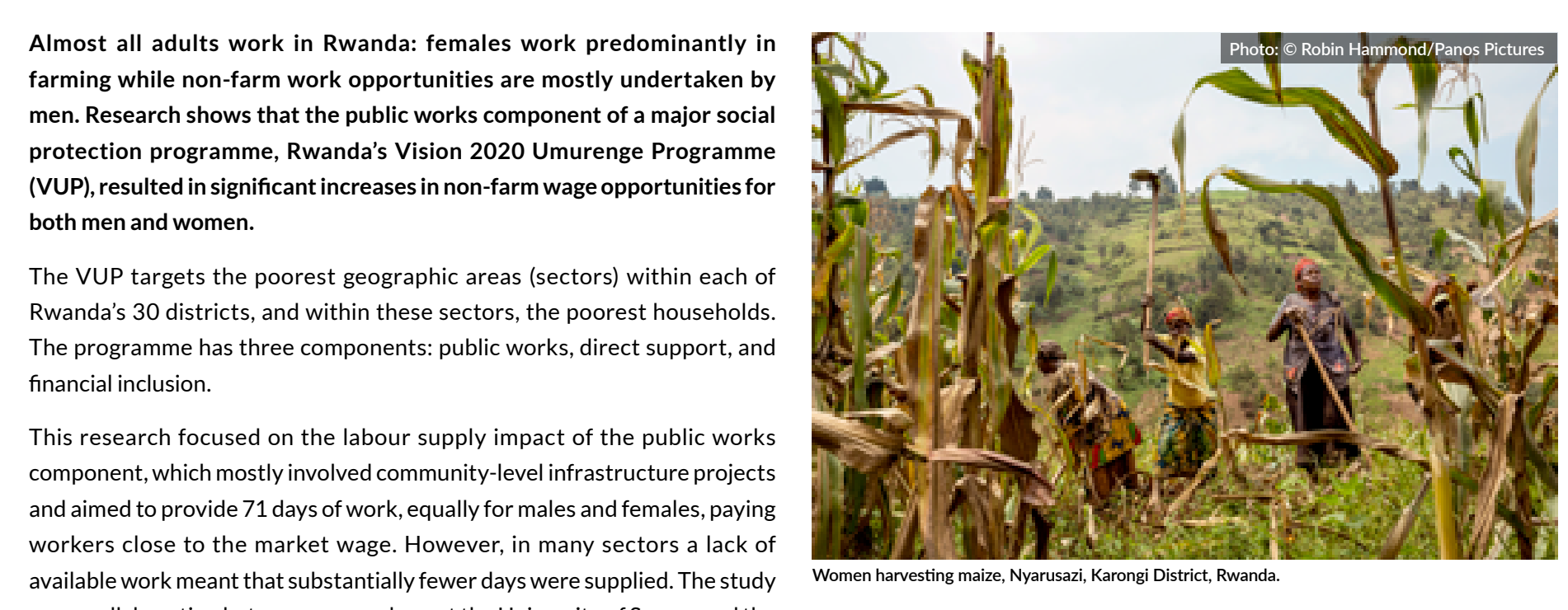

available work meant that substantially fewer days were supplied. The study was a collaboration between researchers at the University of Sussex and the Institute of Policy Analysis and Research (IPAR) in Rwanda.

The researchers used data from two waves of a large-scale multipurpose household survey from 2010/11 to 2013/14 and studied the changes in nonin sectors where the VUP was highly active with other sectors where the in sectors where the VUP was high
programme was not implemented.

The raw data confirms that almost all adult women and men work, and most have more than one activity. Women work almost exclusively in agriculture, mainly on their family farms, but also as wage labourers. The majority of men also work in farming but many more of them have non-farm wage jobs or non-farm self-employment positions, predominantly in wholesale and retail trades.

In comparing locations that had public works with those that did not the researchers also controlled for sector fixed defects and household characteristics. The analysis shows no significant impact of the VUP on the overall labour supply of women or men and no impact on the numbers
undertaking agricultural work, both of which were already very high. But it undertaking agricultural work, both of which were already very high. But does show a significant and quite sizeable increase in the numbers of those undertaking paid non-farm jobs, by 6-13 percentage points for women and
$11-20$ percentage points for men. While the size of the increase is higher 11-20 percentage points for men. While the size of the increase is higher for men, so few women were doing these activities at the baseline that this remains a notable change. There are no significant increases in the number of jobs people undertook, nor in hours worked as a result of the sector's participation in the public works scheme.

Disaggregating the sample by education, these effects are observed for individuals who are more highly educated or come from households with a

\section{SEE ALSO}

Kindness, H. (2011) Vision 2020 Umurenge Programme, Rwanda. Local Development
Support tund Annual Report 2009/10, January

Ministry of Local Government (MINALLC) (2009) Vision 2020 Umurenge Programme
(VUP) Public Works Operational Framework and Procedure Manual, Revised version, 2 January

Vision 2020 U Umurenge Programme (VUP), Rome: Food and Agriculture Organization World Bank (2016) International Development Association Program Document for a Proposed Development Policy Credit to the Republic of Rwanda for the Third Social
Protection System (SPS-3), World Bank Report 108935-RW, 3 October, Washington
Protecting dignity with jobs and social security

Dignity is a foundational value in the South African Constitution. However, research involving lone mothers revealed that although some participants viewed employment as conferring dignity, others had experienced it as erosive of dignity. Social security can play an important role in supporting caregivers whether they are in or out of work.

Low-income lone mothers in South Africa are expected to be both the breadwinner of the family, and to provide care for their children. These dual and often competing expectations occur in the context of high levels of poverty and unemployment, amid pejorative discourses around lone motherhood and social security receipt.

A study was conducted in 2011-13 by researchers at the University of Oxford (UK), the University of the Western Cape, and the Human Sciences Research Council in South Africa to explore the lived experiences of lone mothers with reference to the role of social security in protecting their dignity. The South African Constitution commits to protecting and respecting dignity South African Constitution commits to protecting and respecting dignity
and to the progressive realisation of access to social security. Currently, in and to the progressive realisation of access to social security. Currently, in South Africa there is no social assistance for adults of working age unless
they are disabled. However, there is a means-tested benefit for children of they are disabled. However, there is a means-tested benefit for children of low-income caregivers - the Child Support Grant (CSG) - which is payable
for children of caregivers with an income below a specific level. Low-income for children of caregivers with an income below a specific level. Low-income mothers feel especially pressured to work, not only because the CSG is too
small to meet the needs of the child (and does not include a component for small to meet the needs of the child (and does not include a component for their own material needs), but because of the dependency culture discourse in communities and the country in general.

Sixteen in-depth interviews were undertaken in the Eastern Cape and Western Cape provinces with low-income female caregivers together with 36 focus groups comprising nearly 200 lone mothers. Interviews were also held with senior policymakers, and social attitudes were explored more broadly in relation to dignity, poverty and social security. Results were widely disseminated to different stakeholder audiences.

The participants gave examples of dignity 'in practice' that included being valued and respected, and able to fulfil important roles in life - particularly that of caregiver - and provide for themselves and others. Poverty was described as erosive of dignity.

The CSG helped to protect dignity insofar as it contributed to the cost of raising a child. However, participants raised issues about the burdensome raising a child. However, participants raised issues about
application process, negative attitudes, and its small size.

Some lone mothers with older children said they experienced a modicum of respect from family members with whom they lived because of the CSG income explaining that they were able to share the food purchased.

Many strategies to survive poverty were described as being detrimental to their sense of dignity, particularly begging, demeaning work for family and neighbours, tolerating precarious employment, and transactional sex: 'We endure and persevere, what can we do."

SEE ALSO

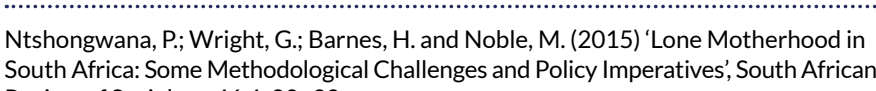
Review of Sociology 46.4: 80-99 Wright, G; Noble, M.; Ntshongwana, P; Neves, D. and Barnes, H. (2014) The Role of
Social Security in Respecting and Protecting Dignity of Lone Mothers in South Africa:

Africa

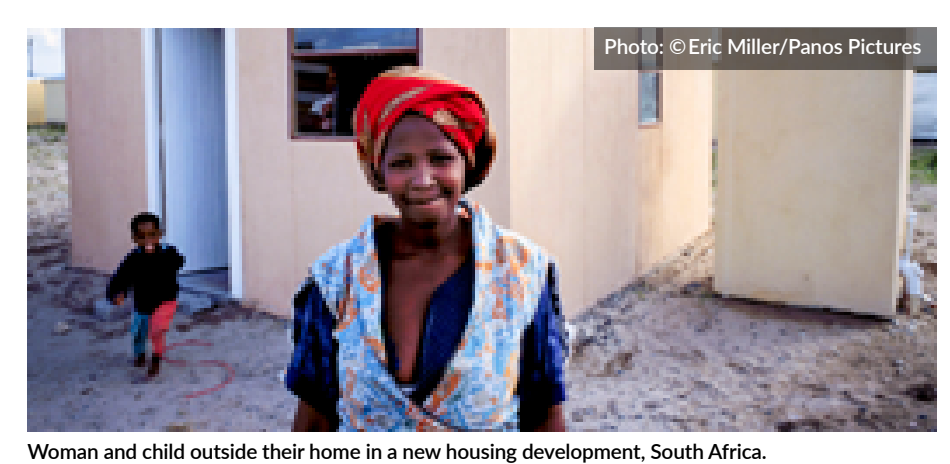

Participants stressed the need for jobs in order to support themselves and their children. They also supported the introduction of social security for caregivers due to high unemployment rates.

The research team argues that comprehensive social security, if implemented in a way that promotes redistribution of wealth in order to protect the dignity of applicants, could play an important role in helping to respectpeople's dignity. In parallel with job creation schemes and affordable (or free) high-quality childcare, social security should be provided to low-income adults of working age - the policies are not mutually exclusive. Extending social security would be advantaceous from a gender perspective given the plight of many female codvantageous from a gender perspective given the plight of many female ren

The team stresses that social security provision for impoverished caregivers with young children should not be linked to an obligation to seek work as they ought to be entitled to choose whether to undertake paid work or do the unpaid work of looking after their child, or a combination of the two. The false dichotomy of independent self-upliftment through paid work versus passive social grant receipt also needs to be challenged: raising a family in a state of poverty - whether unemployed or in precarious employment - is itself extremely hard work, and an expanded system of social security could provide vital support for struggling families.

Project title: Lone Mothers in South Africa: The role of social security respecting and protecting dignity.

\section{Michael Noble}

Mocial Policy, University of Oxford, UK Gemma Wright

rican Social Policy Research Insights, U

Phakama Ntshongwana

The study took place in partnership with researchers based in South Africa David Neves (Institute for Poverty, Land and Agrarian Studies at the

University of the Western Cape) and Temba Masilela and Benjamin Roberts (Human Sciences Research Council).
Final Report, Oxford: Centre for the Analysis of South African Social Policy, University
of Xxford Wright, G.e tal. (forthcoming) 'Lone Mothers' Accounts of the Impact of Poverty on
their Dignity A A South African Perspective', in B. Roberts and Z. Mokomane (eds)
Family Matters, Cape Town: HSRC 


\section{Choice, constraints and the gender dynamics of labour markets in Bangladesh}

Despite steady rates of economic growth across South Asia, female Desour force participation rates remain among the lowest in the world in Bangladesh officil statistics suggest that they went from $24 \%$ in 1999 to just 36\% in 2010 while male rates remained at $80 \%$ or above $(\mathrm{Mah} 1999$ to just $36 \%$ 2016) Research led by the London School of Economics set out to explore this puzzle.

Since this is a region of powerful patriarchal constraints that restrict women's ativities to the domestic domain, cultura noms clearly had a role to play in the explanation. We wanted to investigate whether economic motivations might interact with these norms to differentiate how different groups of women engaged with market forces. We followed a mixed methods approach, using previously collected quantitative data from a DFID-funded research programme, Pathways of Women's Empowerment (2006-2011), to support new rounds of quantitative and qualitative data collection (2014-2017).

Our survey showed that far more women were economically active than recorded by official statistics which failed to capture market-oriente and subsistence work done by women within the home. We also found that women in paid activity were more 'empowered' according to a range of indicators than those in subsistence work or the economically inactive. This result was most consistent for women in formal employment. Yet mo women were not only concentrated in home-based economic activities bu also expressed a preference for such work. At the same time, we found tha patterns of labour market participation are changing - and that the change has been partly driven by policy. Our research suggests different strands of explanation.

- Home-based self-employment has important advantages for women. It is not only considered a more 'respectable' form of work than work outside the home, but it is also more compatible with their unpaid domestic responsibilities. But this generalization has to be nuanced. Women expressed a strong preference for home-based work which earned them an income they could control rather than working unpaid family labour for male-controlled farms and enterprises. Furthermore, concerns with social status meant that those who were willing to take up outside work could face considerable opposition from their families.

- Formal employment, preferably in the public sector, is perceived as a espectable option for educated women from higher status families. is more secure and more likely to be regulated by government rules offering some protection from the exploitation and harassment they could face in other forms of work. Moreover, the fact that women in formal employment mainly work in teaching, health and community work allows it to be constructed as a service to the community,

SEEALSO:

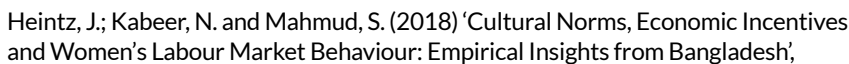
and Women's Labour Market Behaviour: Empirical Insights from Bangladesh',
Oxford Development Studies 46.22 266-289. https://www.tandfonline.com/doi/

pdff/10.1080/13600818.2017.1382464:needAccess=true

Kabeer, N. Mahmud, S. and Tasneem, S. (2018) 'The Contested Relationship Between
Paid Work and Women's Empowerment: Empirical Analysis from Bangladesh', The European Journal of Developoment Research 30.2: 235-251.https:/link.springer.com/ justifying their presence in the public domain. But there are not enough Je these jobs to satisfy demand and bribes were routinely demanded for

them.
Employment by NGOs provide a less preferred, but nevertheless 'respectable' semi-formal alternative. They do not require bribes, but offer less job security Jobs in export garment factories con be done by women with less eduction but is only available to those willing by women with less edration bu is only available to those willing discipline. Moreover, women who do these jobs are seen as disreputable discipline. Moreover, women who do

- The least preferred jobs are in informal daily wage labour - in agriculture, in people's homes or on building sites. These are the only options available to women without education, assets or, in many cases, male support. Wages are low and arbitrarily determined, working conditions are harsh and employers' behaviour can be demeaning. In addition, Working in the public domain with no option of veiling themselves leaves these women open to accusations of immor character and sexual harassment.

While poverty drives many women to work, policy measures have helped to expand the overall demand for female labour. The spread of microfinance has made it possible for many more women to be engaged in income generating activity at home than had been possible in the past. New economic opportunities are drawing others into less traditional forms of work. NGO work is one such opportunity garment factory work is anothe For poorer women asset transfer programs are allowing them to withdraw from demeaning forms of wase labour into home-based nterprise whe government recently the short-term col tro

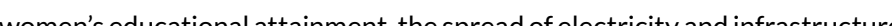

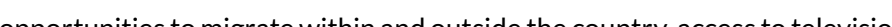
and mob he tech che pho technogy are among the broader factors leading to various for of veiling is nees by the country is also as sen by many as and workoutsis ha son impotant

Project title: Choice, constraints and the gender dynamics of labour narkets in Bangladesh.

\section{Naila Kabeer}

Gender and Developmen

London School of Economics, University of London, UK

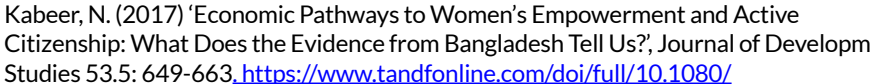

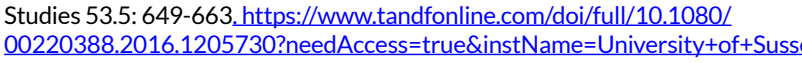
Mahmud, S. and Bidisha, S. H. (2016) 'Female Labor Market Participation in Bangladesh:
Structural Changes and Determinants of Labor Suppply in Selim Raihan (ed). Structcural
Change and Dynamics of Labour Markets in Bangladesh. Studies on Labour and

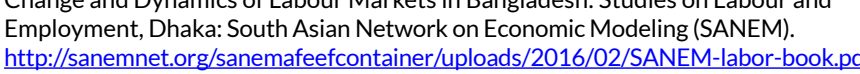

Young women and cash transfers in rural Africa

Young adult women from households and communities that receive poverty-targeted social cash transfers in rural Malawi and Lesotho really want to work They are grateful to receive che bu und receiving 'ree money' and keen to make a productive contribution to their
families and communities.

Since 2006, Malawi has introduced a social cash transfer targeting ultrapoor labour-constrained households and Lesotho introduced the Child Grants Programme for poor households with children. A team of researchers from Brunel University London and other institutions in the UK, Sweden, Lesotho and Malawi undertook qualitative research over a three-year period (2016-18) in rural communities that are receiving these payments. In two case study villages, researchers interviewed all members of households that receive social cash transfers, and also undertook individual interviews and participatory group activities with young people (aged 18-34) from both recipient and non-recipient households. The participatory groups were differentiated by gender.

Of the young women in recipient households, some of those in Lesotho received child grants to support their own children while a small number in Malawi had been targeted as single mothers supporting children. The young people in households receiving cash transfers universally welcomed the additional cash, which enabled them to feel more food secure and buy school essentials for their children. Above all, it meant they were able to feel that they did not stand out in the villages due to their poverty - they could purchase clothes for themselves and their children and soap to keep them clean.

However, young families in receipt of grants almost invariably talked of being resented by those who did not receive money. Often there was little appreciable difference between recipient and non-recipient households, and the situation was exacerbated because the young people were not being expected to work for the money. In Lesotho, the child grants were referred to as seoa holimo, meaning 'money falling from the sky', because they appeared to be random allocations of cash that came with no explanation.

Many of the recipients said they would have preferred to work for the money. Some indicated it would have been better directed specifically at productive investment, enabling them to build income-generating businesses, either individually or collectively. They also pointed to the development needs of their communities - for example, having better roads and bridges to enable their children to walk safely to school, and reforestation projects to stop rocks falling onto and damaging houses from the hillsides above. Employment locally was in very short supply but aspired to by all, and there was work that clearly was in very sh

Both cash transfer schemes envisage the ultimate beneficiaries to be children. Money is given to adult household members - generally parents or grandparents - for this purpose.

SEE ALSO:

Brown, C., Ravallion, M. \& van de Walle, D. (2018). A poor means test? Econometric
targeting in Africa. Journal of Development Economics.https://doi.org/10.1016/.: deveco.2018.05.004

Ellis, $F$. (2012). 'We Are All Poor Here': EConomic Difference, Social Diviviveness and
Targeting Cash Transfers in Sub-Saharan Africa. Journal of Development Studies, 48(2) Targeting Cash Transfers in Sub-Sataharan Africa. Journal of $\mathrm{f}$
201-214.https://doiors/10.1080/00220388.2011.625408

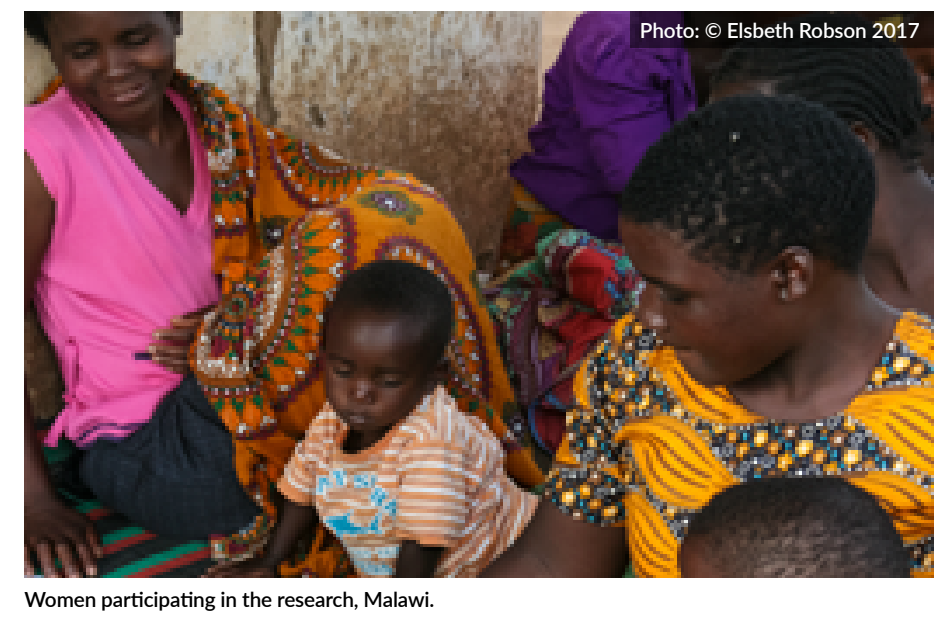

The money paid to parents is undoubtedly spent on children, but neither community viewed children as the principal beneficiaries of the grants. ather, the money was seen to go to parents (male and female) and to trench their responsibilities for their offspring, representing a shift of caring sponsibilities away from extended families toward nuclear households. The 作 to the stereotypical Western image of ma regiver. While young men may have felt greater shame that they (as strong Whs were receiving unearned income, selves as providers and not simply nurturers young men and young women were keen to work.

Itimately, cash transfers are a useful means of supporting impoverished young women materially to fulfil their expectations as parents, and enabling them to experience some level of dignity. But young women also want to play productive role in their families and communities. Culturally, income earned through work is much more respected, and motherhood is associated with providing for the household and not simply day-to-day childcare. Moreover, young women have ambitions of their own, beyond being able to supply the aterial needs of their offspring Rural employment opportunities are sparse, d young women often have fewer prospects than young men of migrating for work particularly if they have young children. It is important, then that sial protection policies include support for young rural wom to access secil

Project title: Social cash transfers, generational relations and youth poverty Project title: Social cash transfers, gener
trajectories in rural Lesotho and Malawi.

Nicola Ansell

Professor of Human Geography

Brunel University London, UK

Molyneux, M. (2006). Mothers at the service of the New Poverty Agenda: the
PROGRESAOPportunidades programme in Mexico. Gender and Social Policy in Global Context: Uncovering the Gendered Structure of "The Social," $43-67$.https://doi.

http://mmwicashtransfers-youthnet/ 


\section{Women's life choices}

\section{Foreword}

W

omen contribute enormously to economies, whether by doing unpaid domestic work, agricultural work, or participating in challenges in their daily lives, such as difficulty in even having their voices heard or gaining a foothold in job markets. They are subject to violence and discrimination, lack of access to health-care services, and inequalities in education, which in turn impede them from accessing economic in turn impede

According to the Global Education Monitoring Report 2016 produced by UNESCO 63 per cent of women who have not attained even minimal of women w literacy skills live in rural areas in sub-Saharan Africa and Asia. In 2015, the United Nations Millennium
Development Goals Report noted that the large majority of Africa's high rate of maternal deaths majority of Africa's high rate of maternal deaths
occur in the rural areas where only 56 per cent occur in the rural areas where only 56 per cent
of births are attended by skilled personnel. These of births are attended by skilled personnel. These statistics alone paint a startling picture, showing that women, especially those in rural areas, are still disadvantaged despite decades of efforts and progress made to improve their lives.

This collection of ESRC-DFID-funded research identifies critical elements that are important to address if women's and girls' lives are to change for the better. The research looks at the mobility constraints experienced by girls and how a lack of access to means of transport hampers their access to paid work, health services, and schooling. It also identifies the barriers that women face when it comes to attending lifesaving diagnostic treatment or accessing maternal health-care services. Furthermore, it emphasises the significant role of education systems in not only enhancing women's economic opportunities but also in helping to economic opportunities but also in helping to
bridge the gender gap by shaping young people's bridge the gender gap by shaping young
aspirations in their future career choices.

On the basis of this evidence, several key interventions have been identified that will transform the lives of women and girls, especially those in poor, rural, and marginalised populations. For instance, it is vital to find a way to increase the accessibility of disease diagnostic treatment The research also highlights the value of using existing spatial data to tackle exclusion from health-care services. In addition, the research identifies the need to strengthen schoo to strengthen the relationships between school and community, teachersand learners, if we are to increase young women's life choices.

o achieve gender equality and empower all women and girls (Goal 5 of the 2030 Agenda for Sustainable Development), there has to be investment in research. However, for research to have an impact, it is critical that it is linked to policymaking. Research provides much needed evidence for policymakers to design policies and programmes as well as influence the allocation of the requisite resources. This collective research supported by ESRC-DFID will no doubt contribute to the knowledge and evidence that policymakers need to address gender disparities and improve the lives of women and girls.

Adequate policies, programmes, and investments in women's health and education not only lift women's ving standards but also pave a way towards gender equality. Unless women are equipped to reach their for full potential and are empowered to make their own fe choices, the 2030 Agenda Goals will be missed.

Director of Social Development Policy Division United Nations Economic Commission for Africa
Key messages

- Stronger consideration of gendered mobility needs is essential;

- Combine different types of evidence, for example spatial maps and interviews, to improve programme design with an understanding of local realities;

- Work with a range of actors, including being clear about their role as this often results in more meaningful and sustained networks and interventions;

- If education systems are to encourage young people to aspire to alternative futures, governments, donors and development agencies should focus on more than just providing educational resources, but should seek to bring together communities, teachers, and children to better understand the challenges faced by women and girls.

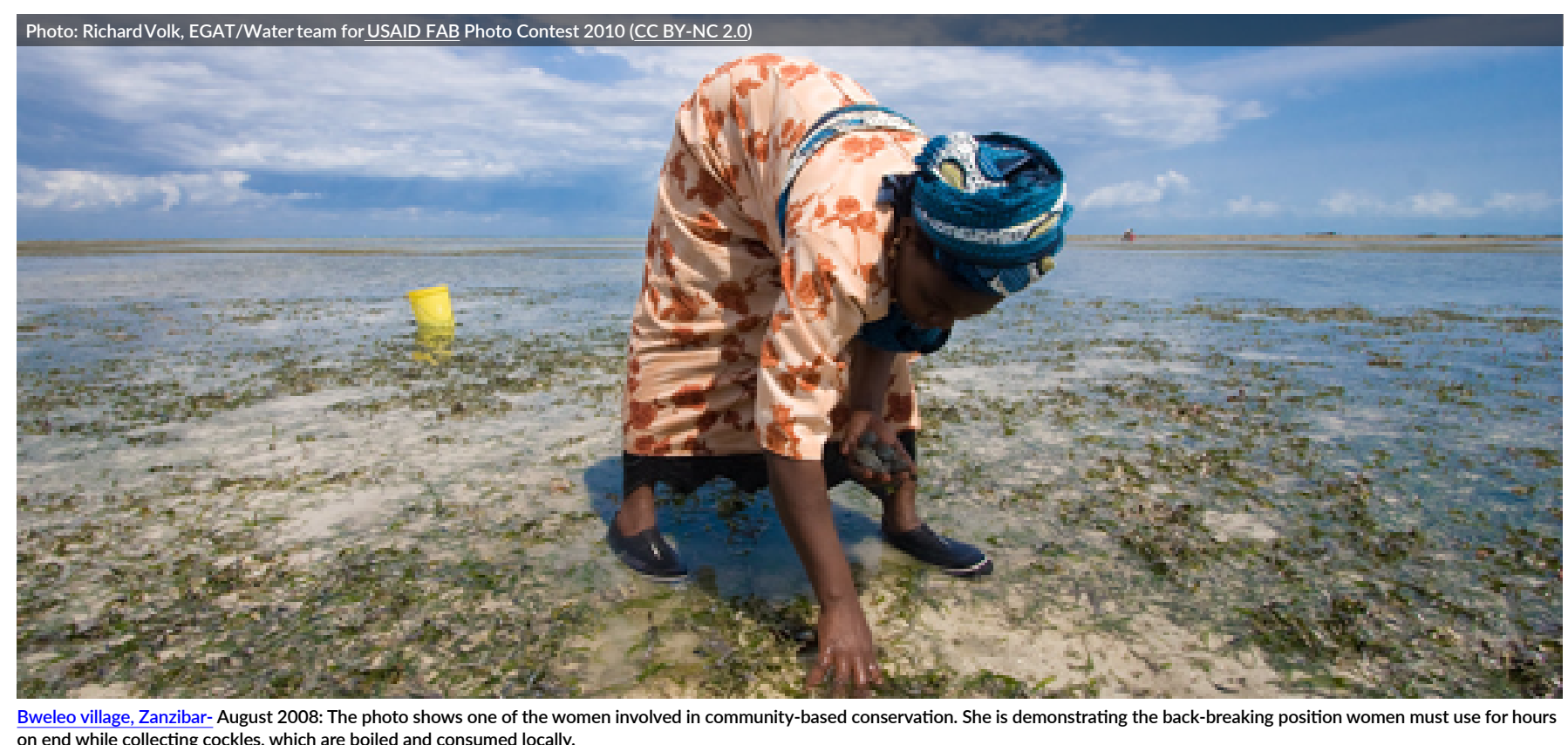

Bweleo village, Zanzibar- Ausust 2008: The photo shows one of the worly

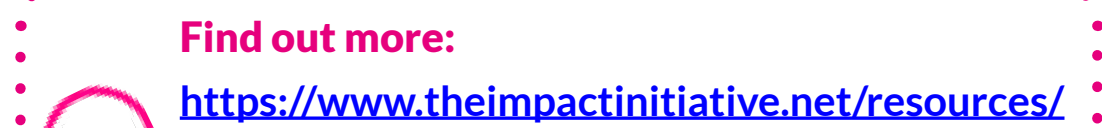

: $\frac{\text { https://www.theimpactinitiative.net/resources/ }}{\text { esrc-dfid-research-policy-and-practice-womens-: }}$ life-choices

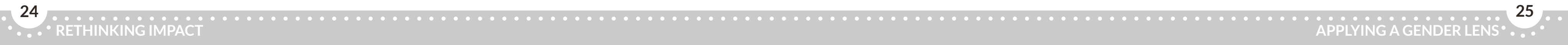




\section{Access to transport is instrumental in shaping girls' lives}

Girls have much less access to means of transport than boys, which greatly limits their opportunities to go to school, receive health care, or get a paid job. Yet the mobility of girls is not an issue that figures often in development debates. Research led by young girls in sub-Saharan Africa (SSA) demonstrates the far-reaching implications of this for girls' lives and life-chances.

Far fewer girls ride bicycles than boys in SSA, mostly because of the lack of resources to buy a bicycle, household work demands, sexual innuendo, an community disapproval. Girls have less resources to pay transport fares which is in part because household work limits their opportunities for wage
employment, and they may suffer harassment if they do travel by taxi or minibus. There is a need to understand the context and constraints for the lack of access to transport for girls in SSA, as it remains one of the biggest barriers for girls to meaningfully participate outside of the home.

The Children, Transport and Mobility in Sub-Saharan Africa project $2006-$ 10), led by Durham University, conducted studies across 24 sites in rura and urban $C$ an Malawi, and South Africa, in collaboration with $\mathrm{C}$ rents University of Cape Coast the University of Malawi and South Africa's Coun

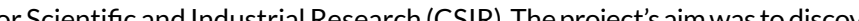
how boys' and sils' daily physicat moblity affects their access to gorts, hervices and life-chances, and to inform policym expecily those working in the transport sector. Schooch 11 and 19 years old nade key inputs, not on as responde but as coinestigars to school, at wat point and markets during frewo Theyprovidedinishts tat Comparison of girls' and boys' movement patterns helped the researchers to Contify constraints experienced by girls, and focus on interventionsthat may mitigate them. The project identified that mobility is more than a technical issue, it is a cultural one as well. Girls are regularly considered as vulnerable and too incompetent and naive to be allowed to travel alone. This significantly affects their access to paid work health services, education, social networks, 'eisure, and wider wellbeing There are severa 'Iffe' i implications thatcone from the lack of mobility and access to transport for girls in SSA:

- Domestic labour: The shortage of cheap, reliable, regular transport in Africa and common absence of water pipes and electricity puts a particular burden on girls as they inevitably bear the brunt of carrying water and frewood for domestic use. Cultural expectation to participate in domestic work also means that girls are less likely to continue in schooling or to do paid work.

- Schooling: Parental concerns around girls' travel safety and vulnerability mean they may start school later than boys and are far less likely to attend secondary school, which generally requires longer journeys.

SEEALSO:

Porter, G. (2011)'IThink a Woman Who Travels a Lot is Befriending Other Men and
That's Why She Travels': Mobility Constraints and their Implications for Rural Wome

Porter, G. et al. (2017) Young People's Daily Mobilities in Sub-Saharan Africa: Moving
Young Lives, London: Palgrave Macrillan

Porter, G. et al. (2012) 'Child Porterage and Africa's Transport Gap: Evidence from
- Paid work: Concerns regarding girls' independent travel (sometimes Pading perceptions that they are potentially promiscuous) reduce their access to paid work opportunities beyond the home settlement.

- Health: Girls report more need for access to health services than boys, especially in the context of teen pregnancy. Their lack of resources to pay for transport can have serious implications, especially when obstetric emergencies occur.

Based on this evidence, the researchers have worked with government, nongovernmental organisations (NGOS), and the private sector to help address Avalible underan poer (t) r. 10 with the Ghana Education CHIDREN, TRANSPORT AND MOBIITY Service to bring gendered mobility issues into teacher
training and the school Q 1) manuals produced by the
African Community Access Programme for policymakers and practitioners across the continent as well as training sessions and draft guidelines for gender mainstreaming prepared for the African Development Bank's transport division.

The evidence demonstrates how constraints on girls' and women's mobility and access to services are pervasive and have far-reaching implications. ey services such as improved school boarding provision for arls, reduction of domestic la a caryin (throol boarding provision for gils, reduction uptak and fuel-efficient stoves) and a stroned water supply, solar energy mabilty a for a r the status In mo training ris to be done if significant change is to be possible.

Teretille.Children, transport and mobilitin sub Saharan Africa: Pe

Gina Porter

Senior Research Fellow, Department of Anthropology Durham University, UK

The study took place in partnership with collaborators in Ghana (Albert Abane), Malawi (Alister Munthali and Elsbeth Robson) and South Africa (Mac Mashiri); Kate Hampshire (Durham University) worked across al contexts.

Ghana, Malawi and South Africa', World Development 40.10:2136-54 Porter, G. et al. (2011)' 'Mobility, Education and Livelihood Trajectories for Young People
in Rural Ghana: A Gender Perspective', Children's Geographies $9.3-4: 395-410$ A list of published papers and other documents from the project is available on the
project website: www.durac.uk/child.mobility/
Maternal health in Ghana: Why geography matters

Improving maternal health is an agreed international development goal. Ghana is a country with a high level of maternal mortality but where rapic enhancement of services is underway. Exclusion from maternity care is a matter of geographical inaccessibility and low status/poverty. Research carried out by the University of Southampton from 2008 to 2011 provided policymakers and women themselves with spatial data to tackle exclusion through maps and other evidence that promoted accountability, as well as information and insight.

Despite maternal health being high on the agenda of the government and international community, Ghana was struggling to make progres on improving maternal health under Millennium Development Goal 5 . The Poverty and Maternal Health in Ghana project used existing geodata to spatially analyse the relationship between poverty and poorly utilised maternal health services in Ghana, and informed the government, funders, development agencies, and civil society of issues associated with accessing maternal health care an health.

It was a collaboration between Northern and Southern-based researchers, government analysts, local and international civil society, and nongovernmental organisations working in the fields of demography, health. and geography.

The research highlighted that distance from health-care services is a key exclusionary factor in rural Ghana, regardless of women's education, ethnicity, and their household wealth status.

Furthermore, at the community level, the research found that encouraging women to attend antenatal care and empowering them with information about available services can be as inportant for access to health care as the poverty level in the community itself.

The project used geographic information systems (GIS) in two case study regions. This use of high-precision data enabled them to quantify 'access to services' much more accurately than before. The model took into account the effect of the local road and footpath network; natural barriers to access such as rivers, swamps, and enclosed areas; and local gradient and topography.

The project had an impact on the GIS research capacity in Ghana through the training of local researchers in both academia and government. This was particularly useful in the government sector, where geodata has since helped to prioritise resources.

The researchers, from the disciplines of public health, social policy, geography, and demography worked in participatory ways from the start of the project.

SEE ALSO

Gething, P. (2010) 'Too Far to Walk: Callibrating Distances to Maternity Health
Facilities for Women Delivering in Ghana Using GIS', Conference Proceeding Abstract Johnson, F.A. and Madise, N.J. (2010)'Targeting Women at Risk of Unintended
Pregnancy in Ghana: Should Geography Matter?', Sexual \& Reproductive Healthcare
Working together they built strong links between women and their healthcare services; they also promoted close collaboration with the Government on diverse stakeholders interested in 作

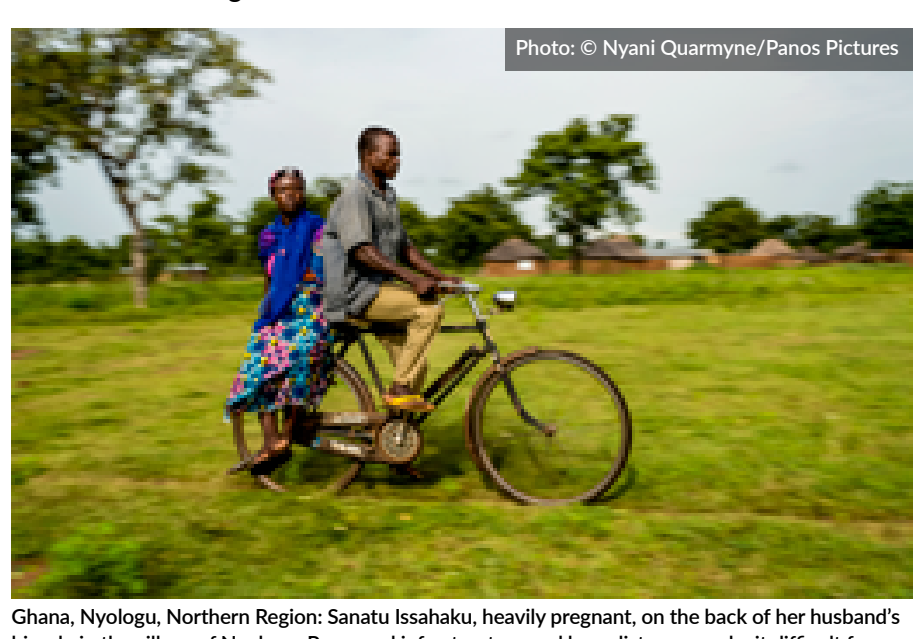
Ghana, Nyologu, Northern Region: Sanatu
icycle in the village of Nyologu. Poor road
woment like Sanatut to access healthcare.

Key Ghanaian academics working in the field of maternal health have also been engaged in research dissemination efforts. In particular, the work has been taken up by colleagues in the School of Public Health, University Gethodologically, the work has been influential in the Ghan Statistical Service.

Following the experience of working more closely with geographers on GIS in maternal health, some members of the research team are now working In national positions in Ghana as well as in international agencies. The dissemination of materials linked to the Atlas of Birth has also been influential project which has launched a live website with information on matern and newborn health for every country in the world including the launch of aspecific Ghanaian atlas. The research team continues to actively engage with key policy actors in the (n) policy, and also accountability, campaigning, and advocacy actions that are men to access health care.

exclusion from care

Zoe Matthews

of Global Health and Social Statistics

Univerity of Southampton, UK

2.1: 29-35

Kehoee S.S. Neilison, J.P. and Norman, J.E. (eds) (2010) Maternal and Infant Deaths
Chasing Millennium Development Goals 4 and 5, London: RCOG Press 


\section{Schools, society, and rural girls' aspirations}

chooling plays a core role in shaping the life-choices of many young women worldwide. Education systems are focused on the future - both nation parents, and students alike as preparation for a future life. Many aspecis of (gendered) future, yet the links between schooling and aspiration are not well understood.

In 2017, researchers from Brunel University London and the Internationa Institute of Social Studies, The Hague, worked with rural primary schools and their surrounding communities in Lesotho, India, and Laos. They wanted to know what role education systems play in shaping young people's aspirations in remote rural areas.

Nine months of ethnographic research was undertaken in two communities in each setting: Korba District in Chhattisgarh, India; Oudomxay Province, Lao and rural Lesotho. Here the team sought to develop a robust understanding of the mechanisms that connect schooling, aspirations and learning outcomes, and to develop ways to better capture these approaches and learn from them They examined curricula and textbooks, but also the ways these are used in the classroom; messages conveyed through other aspects of schooling; and the ways in which children respond.

InLesotho and Laos the reserchers found that textsused in the classroon enderer can tend to represent gils and boys, men a d women, in equal numbers sugest ba ticomestocare How 'naughty' child is almost invariably male.

In Lesotho, the example of Malala Yousafzai, the Pakistani activist for female education and the youngest Nobel Prize laureate, is used to suggest the need to struggle for gender equality. However, a few pages later in the same book, adolescence is discussed in terms that suggest gender differences are biologically determined, while depictions of careers seldom challenge expectations.

The Indian primary school textbooks do even less to confront gender nequalities. Rather, they depict and describe the life stories of (male) nationalist leaders, emphasising their role in addressing class or cast inequalities as opposed to reforming gender attitudes.

It is important to recognise the differences in representation and how they re constructed, as these have an impact on children's life-choices and motivations. The representations of possible futures that children encounter in the classroom are produced through the interaction of national and international actors and reflect aspirations of governments and agencies. ut teachers also play an important role in shaping aspirations, and childre themselves do not passively absorb what is presented to them. Rather, they . lives.

SEE ALSO: Ansell, N. et al. (2018) 'Education Systems, Aspiration and Learning in Remote Rural
Setting', Lesotho Policy Brief (Draft) and individual - and going to school is often understood by teachers, of scholing explicity encourage young people to appre to Mat an sots pcoura in then to aspre tutures not traditionally associted awn ender Theydo to however tell aconsistent story I Laos, text boots

Notably, Lesotho has introduced a new integrated primary curriculum Whention to Lesotho's ext ooks how of them.

Irrespective of different curricula, most children in all three settings saw education as a pathway only to a small range of gender-stereotyped formal sector careers (nurse, teacher, police, soldier). Yet, these expressed aspirations were often held superficially: the children were not consistent over time. Moreover, lacking significant exposure to adults in these occupations, they had little idea about how to achieve them or what life would be like were they successful.

This research is providing an important evidence-based contribution to show how aspirations are produced relationally, between school and community and between teachers and learners. While aspiration may play a role in social change, including the transformation of gender relations, efforts to promote gender-neutral or transformative aspirations are reinterpreted through numerous iterations within the school system. Changes in the formal curriculum alone have limited impact, given the powerful roles played by teachers (particularly in rural areas) in determining what and how to teach, as well as children's own expectations, shaped by their families and communities.

The research identifies that if education systems are to encourage young people to aspire to alternative futures, and to view school as a route to achieve alternative (rural) livelihoods, interventions should target the relationships between school and community, and between teachers and learners. The research team continues to work with policymakers, curriculum developers, and teacher educators in the three countries to consider possible interventions. Discussions of the findings with students, district, state, and national levels in each setting.

Project title: Education systems, aspiration and learning in remote

\section{Nicola Ansell}

Professor of Human Geography

Brunel University London, UK - areas that might be expected to widen the choices available to rural girls. teachers, and parents have been fed into policy workshops at a mix of

\section{Improving women's access to tuberculosis diagnosis services}

Since 2000, access to tuberculosis (TB) diagnosis has saved over 53 million lives (WHO 2018) but its diagnosis rilis travel and staying several days. This presents a challenge for women in poor areas who, as the main caregivers, may not be able to leave children or elderly relatives for the duration, or who cannot get transport on their own to the relatives for the duration, or who can
clinic due to cultural constraints.

In 2009, the World Health Organization (WHO) adopted policies that supported approaches to reduce the time to make a TB diagnosis. The ESRC-DFID-funded research looked specifically at the barriers to diagnosis and treatment in Ethiopia, Yemen, and Nigeria, with a specific focus on women's and men's different experiences. In these countries, patients often abandon the diagnostic process and fail to initiate treatment.

Through surveys, interviews, and group discussions the research team tried to understand the participants' personal perceptions of diagnostic and treatment processes, the barriers they faced, and how services could be
modified to improve access. There were significant costs involved, especially modified to improve access. There were significant costs involved, especially
for clinic fees and transport, and among accompanied adults and those from for clinic fees and transport, and among accompanied adults and those from rural areas.

While many participants explained that women had the same access to health care as men, in reality women faced additional difficulties to attend the services. These barriers included having to request permission from their husband, being unable to travel alone or to access household funds, and holding caring responsibilities.

The participants of this research, particularly women, attended the diagnostic services with companions and were often unprepared for the duration of the process. There were numerous reasons why many patients did not complete the diagnosis, including:

- The cost of the process

- Receiving negative but incomplete smear results

- Having a clear chest $\mathrm{X}$-ray on the first day and then receiving

misleading, or misinterpreting, information from staff.

These reasons were exacerbated in some settings where some patients had to pay additional unofficial fees and were often referred to private services. Patients found non-TB medication and add tional tests in the private sector prohibitive. Many patients highlighted opportunity costs for diagnosis and treatment as an important obstacle. In response, the researchers developed models to identify populations at risk of high expenditure and ways to support those that are the most marginalised to access the services.

As a follow on from the findings of the ESRC-DFID-funded reserch TB REACH grants in Ethiopia, Yemen, and Nigeria have tested-out strategies to address the barriers that both men and women face through bringing diagnosis closer to households and communiles. InEthopla, he TB REACH process trains viliage-based heathextension workers (HEWs) to facilitate access to diagnosis, reducing travel and time taken to seek diagnosis and SEE ALSO:

Anderson de Cuevas, R.M. et al. (2014) 'Barriers to Completing TB Diagnosis in Yemen:
Services Should Respond to Patients' Needs'; PLoS ONE 9.9: 105194 Datiks, D.G. et al. (2015) 'Exploring Providers' Perspectives of a Community Based TB
Approach in Southern Ethiopia: Implication for Community Based Approaches', BMC
Health Services Research 15.1: 501 oportunity costs. This approach has doubled TB diagnosis, with significant nereases amongst women.

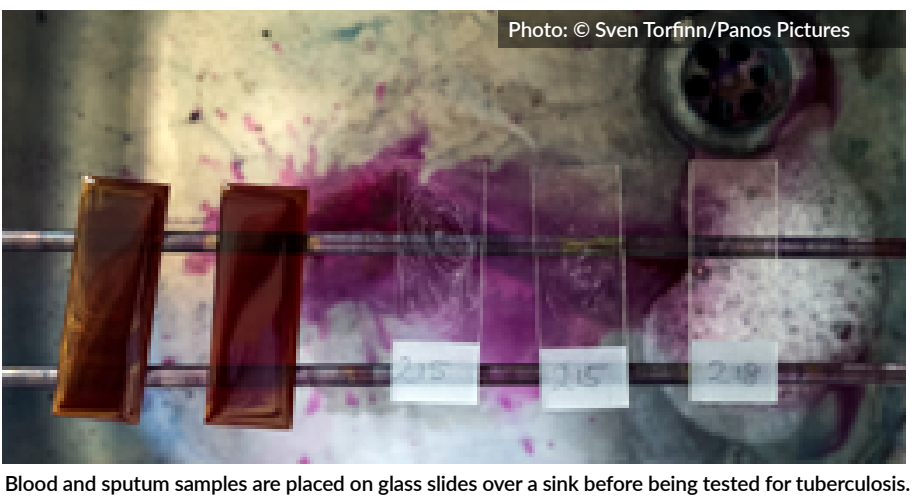

Yemen, the TB REACH project followed-up with contacts of TB patients by visiting households to identify those close to them who had not accessed dagnostic services. These included the elderly, women, and children. The project identified that one in ten households had a second person with TB Who had not accessed the services. In the Nigerian TB REACH process, HEWs dentified adults with symptoms of TB in the congested informal settlements of Abuja and provided diagnostics for TB and HIV where they lived.

Patients in poor communities still face many barriers when it comes to attending and completing TB diagnosis. These barriers disproportionally affect women nd are mediated by traditional and cultural norms including, for example, who s able to travel on their own. New approaches to TB diagnosis can help patients reducing costs; the research shows how vital it is to find ways to complete the diagnosis process in one day and/or bring the treatment closer to where patients live.

Partnership with community health workers has made TB diagnostic and reatment services more accessible to the poor, women, the elderly, and children. Not only was placing TB services within communities much more hospitable and acceptable to families with poor access to health facilities, but all providers were also motivated by the clear use of the services so close Project title: Identifying barriers to TB diagnosis and treatment under a
Rew rapid diagnostic scheme. Sally Theobald

Liverpool School of Tropical Medicine, UK

Luis Cuevas

nal Public Health and Epidemiology

Liverpool School of Tropical Medicine, UK

The study took place in partnership with researchers in Ethiopia

(Noliammed Yassin and Daniel Gemechu Datiko), Yemen (NajlaA-Sonboli and worked across all contexts.

and Care Within a Community-Based Intervention in Ethiopia: A Qualitative Study',
BMC Public Health 15: 187 Yassin, M.A. et al. (2013)' 'Innovative Community-Based Approaches Doubled
Tuberculosis Case Notification and Improve Treatment Outcome in Southern Ethiopia',
PLoS ONE 8.5: e63174 WHO (2018) Tuberculosis, World Health Organization 


\section{Automation, Women, and the Future of Work}

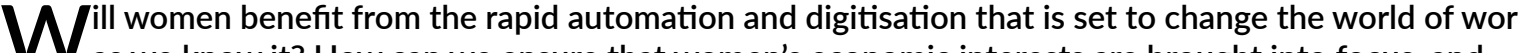
as we knowit? How can we ensure that women's economic interests are brought into focus, and that debates on the future of work are not about the changing relationship between man and machine. but between people and machine? This briefing explores the impact of automation on women and work in developing countries, considering global targets on valuing unpaid care, rights to economic resources, and access and use of information and communication technologies.

\section{Decent work for all in an age of automation}

The eighth Sustainable Development Goal (SDG), jobs in China are at risk of automation in the coming adopted by the global community in 2015, calls for years. Research from the Institute of Development productive employment and decent work for all Studies for the 2017 Digital Development Summit rapidly digitising world, where the majority of jobs institutions are not prepared for such land global are likely to be lost to automation? Recent research rapid change, and are failing to put in place anticipatory predicts that 47 per cent of jobs in the United States, and adaptive measures to cope with its impact. 85 per cent of jobs in Ethiopia and 77 per cent of

\section{Gender, work, and automation}

Research shows that men and women will not equally working-age adults classified as being outside men stand to gain one job for every three jobs lost to technological advances, while women are expected The broader framing of debates on automation to gain one job for every five or more jobs lost. On the inevitably reflects deeply embedded sexism in other hand, as social skills are particularly important society. For example, why is Amazon's virtual artificia in high-paying jobs that are difficult to automate, the intelligence assistant, Alexa, female? What will be the shift in women's employment towards social skill- impact of such sexualised robots on the objectification intensive occupations may mean women actually of real women and girls? Research has shown that benefit from automation. Research from the United sexism is 'hard-wired' into the online systems we States shows that the three occupations expected to use every day. For example, gender stereotypes care aides, registered nurses and home health aides. nannies are female, while architects and philosophers Much of the debate on the future of jobs has aremale.Overall,theseissuesreflectbroaderstructura focused on the formal sector with little attention inequalities experienced by women in employment paid to the impacts of automation on the two billion

How will automation impact on decent work for all?

Against this backdrop, it is clear that the achievement of SDG and girls'. This briefing explores the impact of automation 8 by 2030 will be impossible without considering the risks and on three of the targets under SDG 5, recommending how benefits of digital technology and automation. But this in turn governments, businesses, civil society and others can ensure will be unachievable without paying attention to gender in line with SDG 5: 'achieve gender equality and empower all women

1. Value unpaid care work

SDG Target 5.4: Recognise and value unpaid care and domestic work

Care work is a key contributor to women's lack of economic to look after elderly people - taking on work that is currently empowerment. Women endure the disproportionate burden typically performed by poorly remunerated women -is this what of unpaid care work at home, and also experience low wages society wants? Robotic systems cannot offer empathy or shared for paid employment in the care economy. IDS research experiences. The Engineering and Physical Sciences Research by Deepta Chopra has demonstrated a strong inverse link Council's(EPSRC) Principles of Robotics warns that robots must between the amount of time that women and girls spend on be regulated in a way that ensures they do not exploit vulnerable unpaid care work and their economic empowerment. Many users. As automation develops, social science researchers must women face a double burden of time poverty - through engage with these principles and consider ways to quantify and discrimination in the labour market and also in the drudgery explain the impacts of these changes to a broader population. that is found in domestic responsibilities. Women also face significant barriers in accessing formal employment, such as to formal sector jobs that are often only found in large cities.

Care work often appears in debates about automation in terms of the potential for humanoid robots to be used as person assistants and companions. Yet is it desirable or even ethical fo care to be automated? Caring labour is typically devalued, but it also offers its own emotional rewards as people derive pleasure from the wellbeing of others. While robots may soon be able Rather than seeking to automate the burden of care policymakers and governments should instead be lookin to redistribute the burden of unpaid care work from poor families to the state through provision of public services, infrastructure and care-sensitive social protection. In recognition of this, the International Labour Organization
(ILO) calls for decent work for care professionals, including domestic and migrant workers (see Box 1)

2. Work towards equal access to economic resources

SDG Target 5.7: Undertake reforms to give women equal rights to economic resources The International Monetary Fund estimates that 865 million to their economies, and 94 per cent of these women live in developing countries. In many countries, distortions and discrimination in the labour market restrict women's options for paid work. Research shows that when women try to
overcome these barriers by starting their own businesses,

matrimonial and inheritance laws and/or cultural practices, lack of access to formal financial mechanisms, and limited mobility environment and policy frameworks are in place women entrepreneurs become an important source of economic growth and employment. (International Labour Office: 2015:3) many face obstacles: The obstacles to women starting and growing a business include discriminatory property

\section{Box 1: Gender inequalities in employment}

- Income: Globally, women's earnings are 77 per cent of men's, with the gap widening for higher-earning wome (International Labour Organization 2017)

- Pay equity: Without targeted action, pay equity between women and men will not be achieved before 2086 (International Labour Organization 2015)

- Participation: The global labour force participation rate for women stands at 49 per cent, nearly 27 percentage points lower than the rate for men (International Labour Organization 2017)

- Geography: The largest gender gap in participation rates (31 percentage points) is faced by women in emerging economies such as Brazil, Indonesia, South Africa and Turkey (International Labour Organization 2017)

- Quality: In emerging economies, female workers are typically employed in less-productive and lower-paid sectors, their jobs are more insecure and they are at higher risk of extreme low pay than men (Organisation for Economic Co-operation and Development 2016) 
The concept of a Universal Basic Income (UBI) - a flat rate salary distributed to all citizens - has become increasingly popular as a means to mitigate the impacts of automation
on employment. UBI proponents suggest income security could lead to people spending more time on things they actually care about and improving society, and thus see an increase in creativity and innovation. How to make UBI work the impact of a UBI trial in India showed that such a scheme had a positive impact on women's economic citizenship. Women were not only able to increase and diversify their economic roles and acquire assets, but they also experienced an increase in critical consciousness and empowerment.

Without forms of social protection such as the UBI, it is likely that women in developing countries will suffer more from the impacts of automation as their jobs come under threat and they are less likely to be able to find alternative sources of employment. In recent years, for example, in countries such as the Philippines, the business process outsourcing (BPO) industry has flourished, delivering services such as backoffice support, animation, software development and data transcription. This sector has been an area where women have
had an opportunity for economic advancement, accounting many of these jobs are at risk from automation - for examp 89 per cent of salaried call centre staff in the Philippines BPO

\section{Promote women's empowerment through digital skills}

SDG Target 5.8: Enhance the use of enabling technology, in particular information and communications

(

The examples above powerfully illustrate the potential developing countries. Without digital skills women are unlikely to benefit from the more senior technological jobs that will remain available when the bulk of BPO jobs are automated But while research shows there has been a rapid increase in women working in the IT industry in India and other BRICS (Brazil, Russia, India, China and South Africa) countries, these women progress more slowly than their male colleagues.

There is a significant gender gap in terms of women's access to digital tools. Globally, women are on average 14 per cent less likely to own a mobile phone than men, and poor urban women are about 50 per cent less likely to have access to the internet than men. The Web Foundation has called for a range of policy the information and services that low-income women will find most valuable and ensuring a public fund for technology development (such as subsidies or incentives for technologica entrepreneurs) is specifically set aside for projects led bywomen Policy outputs on the impact of information and communication technologies (ICTs) in developing countries often promise a causal link between internet connectivity and economic growth, which is arguably implicit in this SDG target. These claims are scrutinised in ESRC-funded research on economic development and broadband in East Africa, finding that the current evidence base is mixed and inconclusive. It is therefore essential that the organisations who make these promises are asked to justify their claims, rather than assuming it is selfevident that ICTs will automatically bring about development.
The researchers found that all policies assume, without information and pricipate in the

Further ESRC-funded research on the impact of mobile phones on young people's lives and life chances in sub-Saharan Africa, highlighted how mobile phones
contributed to youth livelihood strategies, such as through job search, micro-enterprise and providing asafety net. The research finds that while many young people use mobile phones in their search for work, they are not enough to overcome structural inequalities. Low levels of education, increasing competition for jobs and little opportunities for work experience exacerbate unemployment. According to lead researcher Gina porter. 'unless the overall basket of opportunities grows, mobile inoesalities faced by women and girls must be overcome if mobile technology is to promote women's empowerment.

The research also found that girls experienced bullying from boys or older men on their mobile phones. Women's experiences of using ICTs might be compromised by digital harassment. Advocacy organisation Take Back the Tech argues that violence against women in the material world is replicated in the virtual per Institutional responses to this issue are still poor: in 74 per cent of countries surveyed for the 2015 Web Index, law periling ICTs are used to commit acts of gender-based violence.
ICT

\section{Recommendations}

This briefing shows that the impact of automation on women is critically ins briefing shows that the in important in the achievement of the global goal of decent work for all by 20
It has demonstrated that this goal is interlinked with other SDG targets on It has demonstrated that this goal is interlinked with other SDG targets on gender equality in employment, economic opportunity, care work and access tackling these issues is all the more urgent.

To promote decent work for all - including women - by 2030, the following recommendations must be implemented

Researchers and analysts

- Researchers must urgently create cross-cutting partnerships across disciplines, geographies and sectors, which address automation's impact on women in developing countries.

- The research community can help broker coordinated, multi-stakeholde responses to the future potential impacts of automation.

das take account of

Civil society and advocacy organisations

Gender-focused advocacy on digital issues must expand, ensuring women can enjoy their right to use digital tools

Global advoca

Global development

.

cexplore the countries.

Policymakers

Policy shifts are needed at a national, regional and global level to ensure digital educationg learning.

Donors and other policymakers must address digital inequalities in their activities to promote women's economic advancement.

- Serious consideration needs to be given to shifts in working practices (such as shorter working weeks) which have the potential to not only address automation-related job losses, but also benefit women with caring responsibilities.
Further reading

dez, K. and Ramalingan B. (2017) Background Paper for the Digita

Summit 2017

Graham, M. (2016) The Impact of Connectivity in

Arrica: Grand Visions and the Mirage of thc

2855398, Rochester NY: Socia

Science Research Network

International Labour Office (2015) Women and .

Gene

Mezzadri, A. (2016) 'Class, Gender and the

Sweatshop: On the Nexus between Labou

Commodification and Exploitation', Third World
Quarterly 37: 1877-1900

Porter, G.; Hampshire, K.; Milner, J.; Munthali,

A.; Robson, E. et al. (2016) Mobile Phones and

Education in Sub-Saharan Africa: From Youth

Practice to Public Policy', Journal of International

Development 28: 22-39

Credits

This Rapid Response Briefing was written by

Becky Faith and reviewed by Pauline Oosterhoff,

was provided by Sarah Nelson and Kelly Shephard.

The material has been funded by the Economic

and Social Research Council and UK aid from the

UK Government. However, the views expressed

do not necessarily reflect the official policies of

Readers are encouraged to quote and reproduce

material from issues of Rapid Response Briefings

in their own publication. In return, IDS requests

due acknowledgement and quotes to be

referenced as above

() Institute of Development Studies, 2017
Find out more:

https://www.theimpactinitiative.net/resources/automation-women-and-future-work 


\section{Gender Evidence Synthesis}

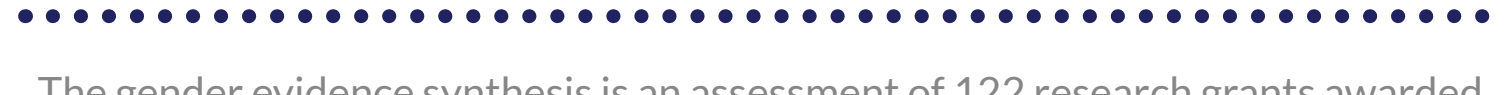
by the ESRC-DFID Joint Fund for Poverty Alleviation Research covering research in Central Asia, Latin America, the Middle East, South Asia, South East Asia and Sub-Saharan Africa. It found that 28 per cent of all awards had an explicit gender focus and a further $32 \%$ per cent included women as part of the study or disaggregated findings by sex.

A gendered understanding of poverty is crucial for exploring its differing impacts. Women, in poverty and the causes of women's poverty ond how poverty is experienced, may differ from men. Neither women nor may, hower are a homogenous group and how powever, experienced depends on otherintersecting issues such as age, class, ethnicity, disability etc. These issues need to be considered in order to get a more nuanced picture of people's lived experiences to help shape policy responses that are relevant and appropriate.
The studies that did have an explicit gender focus provided important new insights into the lived experiences of women's poverty and wider wellbeing. They also demonstrate how a gender analysis can be applied to a 'mainstream' topic such as education to provide insights into wider societal concerns such as violence, and how a gender lens can provide additional interesting insights into how social norms impact on the wellbeing of women and men and girls and boys.

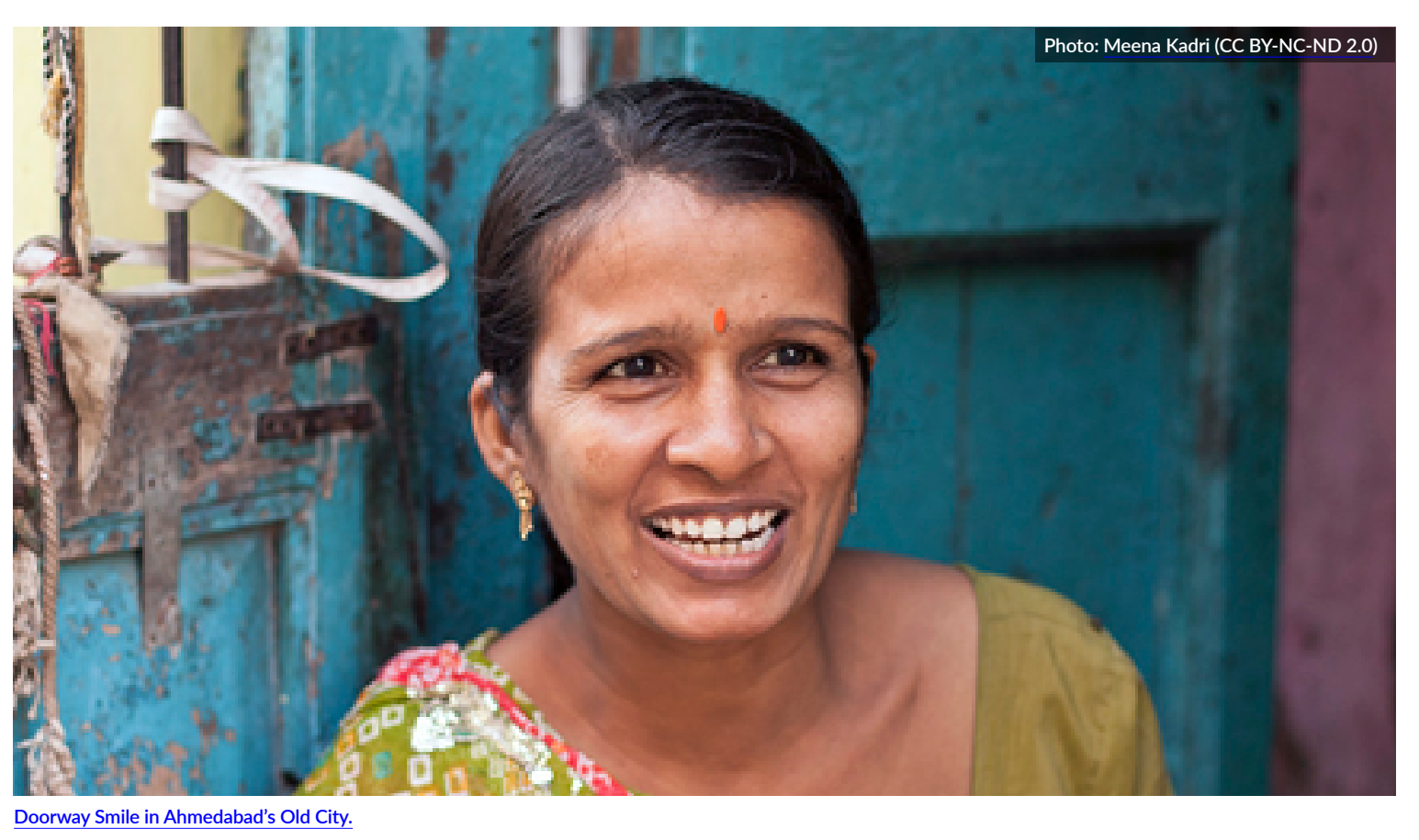

There were some specific key findings to report from

- The starting point for creating highlighting expen's perticipation in paid work highlighting women's participation in paid work that confinemento the private sphere.

-Whilst women are moving into 'traditiona male' areas of work, they still face social stigma for transgressing gender norms, so it is important to explore how employment does, and does not, have the potential to change lives and livelihoods over time. More exploration is also needed on male attitudes to women's income generating activities and the power issues entailed.

-Women suffer more and deal with more diverse forms of shame than men and the studies highlight how shame can compromise women's very sense of humanity. Shame and loss of dignity can be an unintended outcome of social protection programmes and can potentially limit the effectiveness of donor or government responses to poverty.

-While schools and universities can offer opportunities for transforming gender inequalities, sexua harassment and sexu violence may be prevalent in education institutions. To understand this and to capture the ways in which gender norms are shifting over time in these settings, more funding for longitudinal studies would be useful.

- Health providers must do more to ensure women's access to services, recognising how social norms and carer. with disease may also be gendered; limiting

Insights:

- On social norms - the unwritten rules of societies - and how these impede or dictate women's mobility and employment access. Studies also point, however, to how gender relations are complex and shifting in the face of new crises.

- Challenging the assumption that gender equitable access to higher education is enough in the process of women's empowerment.

- The impacts of disease and ill-health on men and women and what hinders their access to services.

- Differing experiences of poverty and well-being, in particular introducing the important, but often overlooked, concepts of shame and dignity.

Find out more:

www.theimpactinitiative.net/new-knowledge-gendered-naturepoverty-and-wellbeing-synthesis-evidence-ten-years-research 


\section{Special Collection}

Social Realities of Knowledge for Development is a special collection of papers which explore critical challenges faced by organisations and individuals involved in evidence-informed development through a diverse set of case studies and thinkpieces. While the dominant themes emerging from the contributions include: building networks and partnerships; contextualisation of knowledge and power dynamics; and modes of knowledge brokerage there are three chapters that particularly highlight the impact on women and gender dynamics that play out within poverty

Find out more:
www.theimpactinitiative.net/
$\vdots$
socialrealities
$\vdots \ldots \ldots \ldots \ldots \ldots \ldots \ldots \ldots \ldots \ldots \ldots \ldots \ldots \ldots \ldots \ldots$

Chapter 3. Translating Health Research to Policy: Breaking Through the Impermeability Barrier

Gita Sen, Altaf Virani, Aditi Iyer, Bhayya Reddy, S. Selvakumar

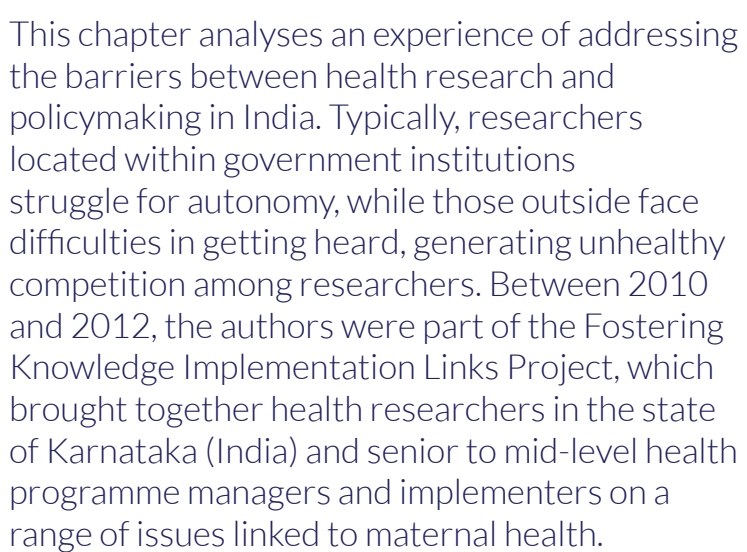

\section{C} reviews and the competence of health-care providers served as a way to raise issues, problematise areas of the programme and policy that were otherwise getting little attention, and provide recommendations for action. IJ

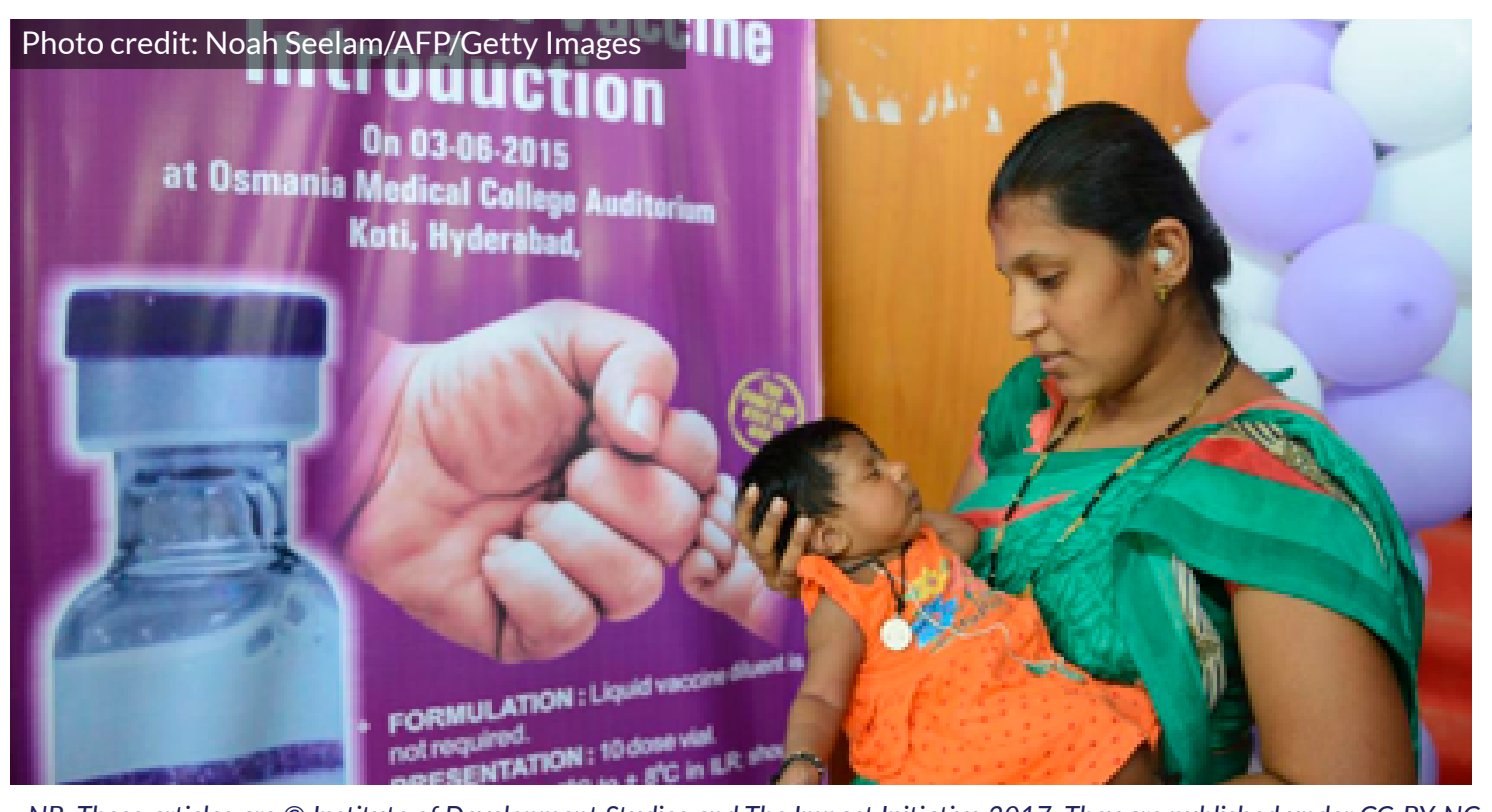

NB. These articles are $\odot$ Institute of Development Studies and The In

Chapter 4. Engaging the Middle: Using Research To Support Progress On Gender, Education And Poverty Reduction Initiatives In Kenya And South Africa

Amy North, Elaine Sara Unterhalter, Herbert Makinda

C6 The project documented many different meanings of gender across the different research sites and highlighted some of the challenges in developing and supporting meanings that stressed equality, human rights and social justice, rather than entailing distancing and blame or a knee-jerk gesture towards noticing girls, often in some essentialised ways that focused vulnerability and embodiment.

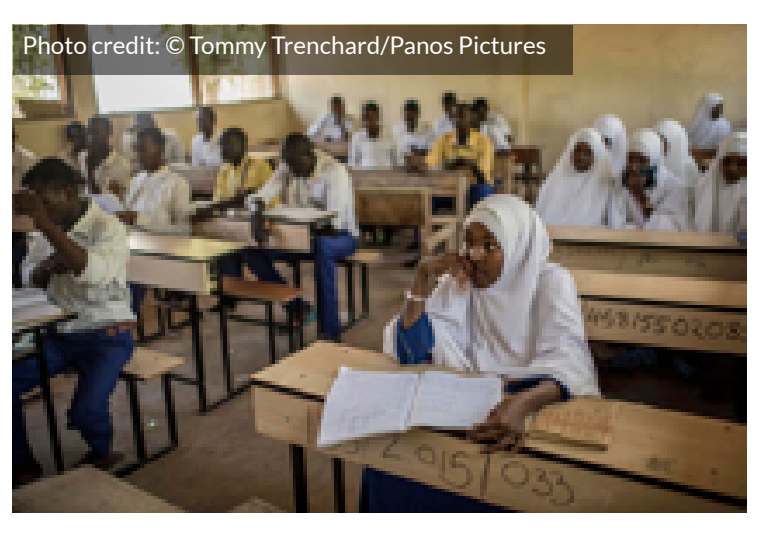

This chapter reflects on the project Gender, Education and Global Policy Reduction Initiatives (GEGPRI), drawing out how the research process catalysed impact among groups who engaged with policy in what was

termed the middle space that lies between centres of global or national-level policy formulations and sites of enactment. The research revealed some of the conditions that might limit the impact of reform initiatives.

Chapter 5. How Collaboration, Early Engagement And Collective Ownership Increase Research Impact: Strengthening Community-Based Child Protection Mechanisms In Sierra Leone

Michael Wessells, David Lamin, Marie Manyeh, Dora King, Lindsay Stark, Sarah Lilley, Kathleen Kostelny

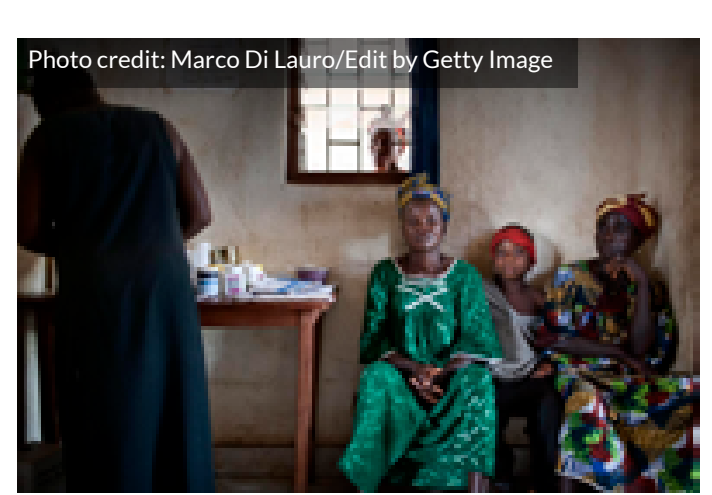

This chapter describes how the inter-agency research facilitated a community-driven approach to addressing teenage pregnancy the Ebola crisis helped shape a new Child and
(6)

Teenage girls reported that because of the intervention, they said 'No' more frequently to unwanted sex. Both girls and boys said that they had learned how to discuss and negotiate with their partners about sex, and also how to plan their sexual activities in light of wider life goals. In addition, boys said openly that they had a responsibility to prevent teenage pregnancy, which contrasted sharply with the boys' previous behaviour.

Family Welfare Policy that featured the role of families and communities rather than formal structures. Then it examines how the social process of the research enabled it to have a 


\section{Key Issues Guide}

This collection of research published by knowledge platform, ELDIS, highlights the collection of research funded by ESRC-DFID on understanding the social norms that restrict women's access to paid work.

The guide provides further reading from research funded by ESRC-DFID on cultural and social barriers, flexible working and shifting norms to demonstrate the breadth of evidence on this subject:

Labouring for global markets: Conceptualising labour agency in global production networks

The article draws on material from South India to examine how people enter garment work as well as the multiple and everyday forms of agency they engage in. We follow a 'horizontal' approach that accounts for gender, age, caste and regional connections in the making and constraining of agency.

Dalits and local labour markets in rural India: experiences from the Tiruppur textile region in Tamil Nadu

For the women in Tiruppur the flexible working model, despite lower pay and limited job security, was often seen as advantageous. It meant a mor social, less stressful working environment, based at home or in smaller factories that often involved working within kinship networks.

\section{Social protection and wellbeing: Food security in Adivasi} communities, Chhattisgarh, India

Q What the ESRC-DFID funded research makes clear is that flexible working conditions for women, while they are still expected to undertake the bulk of unpaid work in the home, offers them some opportunity to engage in paid labour. Ultimately the in is that this mitimately the hop is that this might translate into within the housshold although, for now, this remains to be seen.

A gendered view of efforts to support labour market participation

is needed that recognises the barriers women face because of society's, and their own, different

expectations of work opportunities and their needs at different stages in their lives. The role of men,

and addressing the stigma that they might face, should be a part of this approach. 


\section{Press Cuttings}

The process of organising and communicating information can involve a wide range of intermediaries and outlets. In the Impact Initiative programme we have worked with the global media to produce several targeted articles. Often as part of an event, and in collaboration with NGOs and other researchers these pieces have been opportunities o engage in a larger conversation relevant to public audiences. Issues that have been addressed include: Period poverty; child marriage and supporting mothers.

\section{Devex: Child marriage campaigns are missing the point}

11 October 2017

Nicola Ansell (Brunel University) draws on research funded by ESRC-DFID in Malawi and Lesotho to highlight the fact that applying a universal age limit to marriage fails to acknowledge the context and unique scenarios in countries and communities.

\section{Co}

My many interviews with young women about marriage reflect a diversity of experiences. Mapoka, in Lesotho, talked about her marriage as the saddest moment in her life. She had to leave school. She struggled hard to find food for her young family and had to cope without the support of her mother in her new home. Neither her in-laws, nor even her husband offered her any help. This picture corroborates what I learned from other young women in Lesotho, who told of having to move to live with their in-laws, often in a village they'd never visited, and sharing their lives with unemployed husbands, struggling to provide for themselves and their families. D)

\section{Read more:}

www.devex.com/news/opinion-child-marriage-campaigns-are-missing-the-point-91262

\section{Project Syndicate: Demystifying menstruation}

\section{April 2018}

In collaboration with Gabby Edlin, founder of Bloody Good Period, Catherine Dolan (SOAS, University of London) Julie Hennegan (Johns Hopkins Bloomberg School of Public Health) shared the findings from their study with adolescent girls in Uganda, on menstruation.

\section{(l)}

We need solutions that are based on facts. Too often, biased assumption guide policymaking. When programs are developed in conjunction with rigorous research, the effect can be dramatic. For example, a joint SOASOxford study on menstruation in Uganda found that adolescent girls often missed school because they didn't have access to clean sanitary products. But when reusable sanitary pads and education about menstruation were provided to girls in eight schools, attendance rose by an average of $17 \%$.

\section{Read more:}

www.project-syndicate.org/commentary/female-empowerment-managing-menstrualsanitation-by-catherine-dolan-et-al-2018-04

\section{New Statesman: Why tackling period poverty is an issue for everyone}

7 February 2017

Following on from an engaged roundtable discussion as part of the ESRC Festival of Social Science in November 2018 on demystifying menstruation UK - Uganda, the panellists, Catherine Dolan, Mandu Reid (The Cun Effect and UK Women's Equality Party) and Emily Wilson-Smith (Irise International) wrote a piece building on their discussion on the universal nature of 'period poverty' and the need for multiple approaches and understandings in addressing it.

\section{Q}

The failure to support women to manage their periods is a loss for society at large. Assumptions that women are less efficient while menstruating, the stigmatisation of a natural life process and the relative underdevelopment of the reusable menstrual product market must all be addressed. Politicians and policymakers need to be a driving force behind making a change. This is not just a feminist issue. This is a human issue. 1

\section{Read more:}

www.newstatesman.com/spotlight/healthcare/2019/02/why-tackling-period-povertyissue-everyone

\section{Project Syndicate: How social protection can empower} women

2 May 2019

After participation in the UN Women's 63rd Commission for the Status of Women, which asked: 'Does Poverty End at Employment? the Phakama Ntshongwana (Nelson Mandela University), Nicola Ansell (Brunel University) and Keetie Roelen (Institute of Development Studies) wrote a timely piece that argued the need to provide women not only with job opportunities, but also social support that accounts for the true extent of their responsibilities.

\section{c}

Evidence from around the world demonstrates the urgent need for socialprotection policies and initiatives that enable women not just to survive, but to thrive. This means giving women the support they need to participate in the labour force - including education and training - while taking into account the true extent of their responsibilities. Above all, it means empowering women to choose the balance between employment and caregiving that works best for them.

Read more:

www.project-syndicate.org/commentary/rethinking-social-protection-for-womenby-phakama-ntshongwana-et-al-2019-05 



\section{THE IMPACT INITIATIVE}

THIS BOOKLET PROFILES THE RESEARCH AND IMPACT FUNDED BY THE ESRC-DFID STRATEGIC PARTNERSHIP WHICH EXPLICITLY FOCUSES ON GENDER INEQUALITY, BUT ALSO PROJECTS WHERE THE GENDER DYNAMICS EMERGED DURING THE COURSE OF THE WORK. THIS COLLECTION OF RESOURCES HIGHLIGHTS THE MANY DIFFERENT OPPORTUNITIES AND COLLABORATIONS THAT SHOW HOW A GENDERED LENS CAN TRULY HELP UNDERSTAND THE REALITIES OF PEOPLE AROUND THE WORLD.

INFO@THEIMPACTINITIATIVE.NET WWW.THEIMPACTINITIATIVE.NET Y @THE_IMPACT INIT \#IMPACTLESSONS

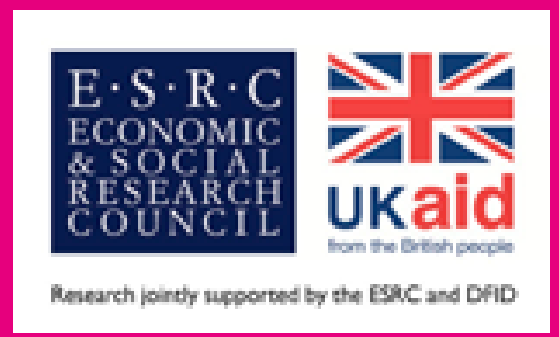

